DONALDO JORGE FILHO

\title{
Importância da podobarometria computadorizada na prescrição de órteses para redução das hemartroses de repetição dos tornozelos, em pacientes hemofílicos
}

Tese apresentada à Faculdade de Medicina da Universidade de São Paulo para obtenção do título de Doutor em Ciências

Área de Concentração: Reumatologia

Orientador: Prof. Dra. Linamara R. Battistella 


\section{FICHA CATALOGRÁFICA}

Preparada pela Biblioteca da

Faculdade de Medicina da Universidade de São Paulo

Creprodução autorizada pelo autor

Jorge Filho, Donaldo

Importância da podobarometria computadorizada na prescrição de órteses para redução das hemartroses de repetição dos tornozelos, em pacientes hemofílicos / Donaldo Jorge Filho. -- São Paulo, 2004.

Tese(doutorado)--Faculdade de Medicina da Universidade de São Paulo.

Departamento de Clínica Médica.

Área de concentração: Reumatologia.

Orientadora: Linamara Rizzo Battistella

Descritores: 1.HEMOFILIA A/complicações 2.HEMOFILIA B/complicações 3.TORNOZELO/fisiopatologia 4.HERMATROSE/complicações 5.MARCHA 6.DIAGNÓSTICO POR COMPUTADOR/métodos 7.INTERPRETAÇÃO DE IMAGEM ASSISTIDA POR COMPUTADOR/métodos 8.APARELHOS ORTOPÉDICOS 10.SEGUIMENTOS 


\section{DEDICATÓRIA}

Dedico este trabalho à minha esposa, Sílvia, pelas três décadas de infinita paciência com minha obsessão pelo trabalho, e aos meus filhos, Daniel, Diogo e Marcos, já pensando na carreira universitária, em quem deposito toda minha esperança em carreiras brilhantes com retidão, seriedade e empenho profissional. 


\section{RECONHECIMENTO}

$>$ À colega, Profa. Dra. Eloísa S.D. Oliveira Bonfá, da Disciplina de Reumatologia da Faculdade de Medicina da USP, que desde o princípio acreditou neste trabalho e me abriu as portas de sua disciplina para a realização do doutorado, meu objetivo desde que me graduei em medicina na Universidade Federal de Juiz de Fora, MG. 


\section{RECONHECIMENTO}

Ao colega, mestre e amigo, que me abriu as portas de sua disciplina para que eu pudesse começar a realizar o sonho da pós graduação

> Prof. Dr. Danilo Masiero da Disciplina de Fisiatria da Escola Paulista de Medicina, UNIFESP, que me propiciou a realização do mestrado 


\section{RESPEITO E GRATIDÃO}

À minha orientadora, Prof. Dra. Linamara Rizzo Battistella, diretora de rara eficácia, orientadora arguta, que sabe como ninguém, por ações e palavras, motivar a todos que com ela têm o privilégio de trabalhar a produzir sempre mais e melhor. 


\section{AGRADECIMENTO}

Ao Prof. Dr. Ulysses Dória Filho, do Instituto da Criança do HC-FMUSP, pela paciência em transmitir a difícil arte da análise estatística para um indivíduo com dificuldades inatas em lidar com números como eu e, ainda mais, por ter analisado os dados desta pesquisa e sugerido o método estatístico aqui utilizado. 


\section{AGRADECIMENTO ESPECIAL}

À Dra. Claudete Lourenço, associada a este trabalho desde o princípio, colaboradora incansável nas avaliações clínicas dos hemofílicos que participaram deste estudo. Esta tese também é sua! 
Ao colega de muitos anos na Divisão de Medicina de Reabilitação do HC-FMUSP, José Brenha Ribeiro Sobrinho, incansável na busca do saber, exemplo de dedicação ao estudo e ao trabalho. 


\section{AGRADECIMENTOS}

Aos residentes e estagiários que participaram conosco das avaliações podobarométricas. Sua ajuda foi de grande valia na obtenção dos registros que levaram aos resultados expressos neste trabalho.

Aos amigos Moacir Farias Bezerra e Jeane Cleide Costa Vieira, especialistas em informática da Divisão de Medicina de Reabilitação - DMR - do Hospital das Clínicas da FMUSP, professores dedicados de um aluno com dificuldades de aprendizagem.

Ao jovem mas experiente engenheiro José Augusto Fernandes Lopes, do laboratório de avaliação do movimento da DMR, pelo entusiasmo com que nos auxiliou no desenvolvimento do material iconográfico utilizado neste trabalho.

Às bibliotecárias Judith Cardoso de Sá de Oliveira e Maria Amélia Benetasso Villanova, da biblioteca da DMR, pelo inestimável auxílio na busca de material de pesquisa bibliográfica e na revisão das referências bibliográficas. 
Aos colegas responsáveis pelos serviços de hemoterapia das entidades relacionadas abaixo, por terem acreditado e apoiado nossa pesquisa, enviando-nos seus pacientes

> Hospital Brigadeiro de São Paulo

> Fundação Pró Sangue do HC-FMUSP

$>$ Hospital São Paulo da UNIFESP

$>$ Centro Infantil de Investigações Hematológicas Dr Domingos Aldemar Boldrini, de Campinas

$>$ Centro de Hematologia de São Paulo.

Aos membros da banca examinadora do Prêmio Daniel Rodarte, do Centro Infantil de Investigações Hematológicas Dr. Domingos A. Boldrini, por ter atribuído às "investigações preliminares" desta pesquisa o primeiro lugar entre os trabalhos de profissionais da saúde, no ano de 2001. Essa premiação em muito contribuiu para divulgar nosso trabalho junto aos serviços dedicados ao cuidados dos hemofílicos em nosso país. 


\section{AOS HEMOFÍLICOS}

Motivo maior deste trabalho, a certeza de que continuaremos nossas pesquisas no sentido de prover, por todos os meios ao nosso alcance, alívio das dores e melhores condições funcionais, com a finalidade de melhorar-Ihes a qualidade de vida e evitar as incapacidades, objetivo maior da Medicina de Reabilitação. 


\section{SUMÁRIO}

1. INTRODUÇÃO

2. OBJETIVOS

Hipóteses deste estudo

Determinação do tamanho da amostra

3. CASUÍSTICA E MÉTODOS

3.1 Casuística

3.2 Método

4. RESULTADOS

5. DISCUSSÃO

6. CONCLUSÕES

\section{ANEXOS}

Anexo A: Aprovação da Comissão de Ética para Análise de

Projetos de Pesquisa - CAPPesq;

Anexo B: Planilha para coleta dos dados ambulatoriais;

Anexo C: Termo de Consentimento Livre e Esclarecido.

REFERÊNCIAS BIBLIOGRÁFICAS 
SIGLAS E SÍMBOLOS
AR
Artrite Reumatóide
CP
Centro de Pressão
EV
Endovenosa
EVA Etil vinil acetato
FAH Fator(es) Antihemofílico(s)
PC Computador Pessoal
TCP Trajetória do Centro de Pressão
2D Duas Dimensões 


\section{RESUMO}

Jorge Filho, D. Importância da podobarometria computadorizada na prescrição de órteses para redução das hemartroses de repetição dos tornozelos, em pacientes hemofílicos. São Paulo, 2004. Tese (Doutorado) Faculdade de Medicina, Universidade de São Paulo.

As hemartroses, a despeito dos avanços terapêuticos ocorridos na hemofilia, continuam sendo os eventos clínicos mais freqüentes. As hemartroses de repetição, sobretudo nos tornozelos, podem estar associadas à instabilidade articular. Sabe-se que a instabilidade articular pode contribuir para aumentar a frequência dessas complicações e prescrevem-se órteses que limitam muito os pacientes. Diante desse quadro buscamos um instrumento para qualificar os desvios nos tornozelos instáveis durante a marcha, dinamicamente e em tempo real. Essa avaliação permitiu a prescrição de palmilhas de fácil confecção, de calçados com contrafortes posteriores e, nos casos muito instáveis, a associação de órteses funcionais, dinâmicas, para tornozelos. A intervenção realizada nos pacientes constou do exame pela podobarometria dinâmica computadorizada, antes e depois da prescrição das órteses. O uso das órteses prescritas conforme as observações podobarométricas permitiu liberdade na marcha, assegurando estabilidade articular. O número de hemartroses nos tornozelos e o consumo de fatores da coagulação em cada hemorragia, nos 43 hemofílicos avaliados, foi verificado nos prontuários médicos dos pacientes, em suas instituições de origem, nos seis meses pré-intervenção e nos seis meses pós-intervenção. Nos 43 hemofílicos avaliados, a média de ocorrência de hemartroses, que era de 4,81, foi reduzida para 2,53 hemartroses por paciente, após a intervenção. A média do consumo de fatores da coagulação reduziu de 9647,7 IU para 4407,0 IU, com $p<0,001$. Com base na análise dos resultados concluímos que a podobarometria dinâmica computadorizada é um meio diagnóstico útil na prescrição de estabilizadores para os tornozelos dos hemofílicos, contribuindo significantemente para a redução da incidência de hemartroses. 


\section{SUMMARY}

Jorge Filho D. Significance of the computerised pedobarography to prescription of orthosis for repetitive ankle haemarthrosis reduction, on hemophilic patients. São Paulo, 2004. Thesis (Doctorate) - University of São Paulo Medical School

The haemarthrosis, despite the improvement of therapeutic resources occurred in haemophilia, have been the most frequent haemophiliac's clinical event. The repetitive haemarthrosis, speccialy those occurred in ankle joints, could be associated to ankle instabilities.

It is known that the joint instability can contribute to increase the frequency of those complications and are prescribed orthosis which severely limit the patients. Face to these facts, we have searched for an instrument able to qualify the deviations in the unstable ankles during the gait, dynamically and in real time. Such evaluation would allow the prescription of insoles, of shoes with posterior counters and, in very unstable cases, the association of dynamic supports. The intervention performed in the patients was constituted of the computerised dynamic pedobarography examination, before and after the prescription of the orthosis. The use of the prescribed orthosis according to the pedobarographic observations allowed joint stability with gait liberty. The number of haemarthrosis in the ankles and the consumption of coagulation factors in each bleeding of the 43 haemophilic evaluated was verified in the patients' medical records, in their original institutions, in the six months that preceded evaluation and therapeutic intervention in haemophilic patients and during the six months after it. In the 43 evaluated haemophilic patients, the average occurrence of haemarthrosis went from 4,81 episodes before intervention to 2,53 episodes after the intervention. The average coagulation factors consumption went from 9.647,7 IU to $4.407,0 \mathrm{IU}$. The $p$ value is smaller than 0,001 . Based on the analysis of the results, we are able to conclude that the computerised dynamic pedobarography is a useful diagnosis method with a significant contribution to the reduction of incidence of ankle haemarthrosis. 


\section{INTRODUÇÃO}

A deficiência genética dos fatores VIII e IX da coagulação do sangue, conhecidos por Fatores Anti-Hemofílicos (FAH), constitui a base fisiopatológica da hemofilia.

Há duas formas de apresentação da hemofilia. A Hemofilia $A$, ocorre pela deficiência, no sangue, do Fator VIII da coagulação. A Hemofilia B, é resultante da deficiência de Fator IX da coagulação.

O quadro clínico da hemofilia cursa com a ocorrência de hemorragias, espontâneas ou decorrentes de traumas, em qualquer parte do organismo.

As hemorragias são mais freqüentes e mais intensas à medida que os níveis desses fatores da coagulação são menores no sangue. Essa relação ensejou a divisão da hemofilia segundo a gravidade:

1. Hemofilia grave - concentrações dos FAH, na circulação, menores do que $1 \%$

2. Hemofilia moderada - concentrações dos FAH entre $1 \%$ e $5 \%$

3. Hemofilia leve - concentrações dos FAH acima de 5\%.

Para conter os episódios hemorrágicos deve ser reposto o $\mathrm{FAH}$, de modo a regularizar as taxas sanguíneas até uma situação em que não ocorram mais sangramentos.

Os avanços no tratamento, com a generalização da aplicação dos $\mathrm{FAH}$, reduziram sobremaneira a mortalidade associada aos episódios hemorrágicos. 
É sabido que a evolução no fornecimento de componentes do sangue humano, com os elementos necessários a coibir as hemorragias, fez com que pacientes que antes morriam após contusões afetando o Sistema Nervoso Central ou as vísceras internas, pudessem hoje apresentar sobrevida igual à de indivíduos não hemofílicos (LECHNER, 1985 apud SZUCS, 1998). Verificou-se por isso um aumento na incidência das hemartroses

O aumento na espectativa de vida tornou imperiosa a busca de tratamentos adequados para os angramentos articulares.

Esses sangramentos, conhecidos como hemartroses, podem ocorrer após traumatismos, casos que independem da gravidade da doença. Podem ocorrer também hemorragias espontâneas. Há relatos de hemorragias espontâneas, até com freqüência elevada, em pacientes com hemofilia de grau leve, na dependência de fatores externos.

Nos dias atuais, as manifestações mais freqüentes e mais incapacitantes da doença são as hemorragias músculoesqueléticas (RODRÍGUEZ-MERCHÁN, 1997; FELDMAN, 2000).

Segundo HOFMANN P. apud HEIM et al., 1985, 93\% dos episódios hemorrágicos nos hemofílicos ocorrem no sistema músculo-esquelético.

1 LECHNER K., Handbuch der Inneren Medizin. Berlin, 1985.

2 HOFMANN, P. In: Gastpar HFK, ed. Biology of articular cartilage in health and disease. New York, 1980. 
A maior parte dos sangramentos ocorridos nos hemofílicos têm como sede o sistema músculo-esquelético, e mais especificamente as articulações dos joelhos, cotovelos e tornozelos, as quais respondem por 80\% desses episódios hemorrágicos (RODRÍGUEZ-MERCHÁN,1996) . As hemorragias articulares causam limitações progressivas aos movimentos dos pacientes, culminando com a degeneração articular conhecida como artropatia hemofílica. Por ser a hemofilia um distúrbio da coagulação determinado geneticamente, os episódios hemorrágicos costumam ocorrer numa fase precoce da infância (MOLHO et al, 2000).

O joelho, o cotovelo e o tornozelo, em geral nessa ordem, costumam ser as articulações mais freqüentemente acometidas por hemorragias intrarticulares (DIEZ-EWALD e URDANETA,1983). Entretanto, há evidências de que o tornozelo seja a segunda articulação mais afetada (STEVEN, et al.,1986 ; HEIJNEN et al., 1997). Segundo STEVEN et al.,1986, com base na totalidade das hemartroses sofridas por 139 pacientes estudados clinica e radiologicamente, 50,9\% haviam ocorrido nos joelhos, $42,8 \%$ nos tornozelos e $38,5 \%$ nos cotovelos.

A Disciplina de Fisiatria da Escola Paulista de Medicina, da UNIFESP, realizou um estudo retrospectivo analisando 106 prontuários de pacientes hemofílicos, atendidos em consulta inicial no Serviço de Hemofilia da

Disciplina de Hematologia daquele estabelecimento de ensino superior. Esse estudo revelou que as hemartroses nos tornozelos constituíram a maioria $(38,24 \%)$ dos episódios ocorridos na faixa etária de 0 a 10 anos, secundadas pelas hemartroses nos joelhos (20,58\%). Na faixa etária 
entre 10 e 20 anos, as hemartroses nos tornozelos (26,14\%) ficaram pouco abaixo daquelas ocorridas nos joelhos (26,79\%). Na faixa acima dos 20 anos de idade, os tornozelos ficaram atrás dos joelhos $(23,86 \%)$ e dos cotovelos $(22,72 \%)$, com $21,02 \%$ do total das hemartroses descritas nos prontuários estudados entre agosto de 1988 e maio de 1990 (AKOPIAN et al., 1992)

A ocorrência de hemartroses de repetição pode levar, precocemente, à rigidez articular. A membrana sinovial se inflama e esse processo leva à formação de vasos sanguíneos de paredes frágeis que podem romper-se, liberando mais hemácias no interior da membrana sinovial. As hemácias do sangue retido se degradam, liberando íons de ferro que se depositam nos tecidos articulares. O sangue, mesmo em exposições muito limitadas no interior das articulações sinoviais, pode afetar rápida e diretamente o metabolismo da cartilagem, de modo irreversível, sem que ocorra sinovite. Essa constatação faz supor que para que se processe a lesão da cartilagem articular, só é preciso a presença de hemácias e de polimorfonucleares (ROOSENDAAL et al, 2000).

A condição resultante dessa agressão aos tecidos articulares se denomina sinovite crônica hipertrófica. A cápsula articular enrijece e fica com a expansão limitada, o que favorece o aumento da pressão no interior das articulações por ocasião de novas hemorragias. Esse fenômeno interfere estruturalmente nos tecidos articulares, obrigando a buscar alternativas que impeçam a degeneração ósteo-articular. 
Segundo LIESNER et al.,1996, o tratamento ideal para a hemofilia é a profilaxia primária, instituída numa fase bem precoce, na infância. Essa modalidade terapêutica consiste de infusões regulares de doses do FAH que permitam manter taxas circulantes suficientes para evitar hemorragias. Os 27 pacientes observados por esses autores foram submetidos a 3 infusões semanais, endovenosas, do FAH.

Partidários desse tipo de profilaxia recomendam que ela seja iniciada antes que as crianças tenham sofrido hemartroses ou logo após o primeiro episódio sintomático de sangramento intrarticular. Os estudos desenvolvidos no Hospital da Universidade de Lund em Malmö, Suécia, sugerem que essa prática deva ser iniciada antes que ocorra a primeira hemorragia articular, por volta de um ano de vida, quando a criança começa a andar. São dois os objetivos da profilaxia primária em que se utilizam preparações dos $\mathrm{FAH}$, regularmente, duas ou três vezes por semana:

evitar o desenvolvimento de uma "articulação alvo"

prevenir sangramentos mais graves e, desse modo, evitar o aparecimento de lesões articulares crônicas (LJUNG, 1998).

Diversos autores afirmam que a reposição profilática dos $\mathrm{FAH}$ evitam as complicações de curto e de longo prazos dos tratamentos, promovendo a total integração do hemofílico à sociedade (LJUNG, 1998; KREUZ et al., 1998; MOLHO et al., 2000).

KREUTZ et al., 1998, acompanharam 21 pacientes com hemofilias $\mathrm{A}$ e $\mathrm{B}$, moderadas e graves, que receberam tratamento profilático com duração entre 3,1 e 16,1 anos. Esses pacientes, divididos em três grupos 
de acordo com a idade na época do início do tratamento, receberam em média 30 a 50 unidades internacionais (UI) de fator VIII ou IX por, respectivamente, três ou dois dias semanais. As articulações estudadas foram os cotovelos, os joelhos e os tornozelos. No primeiro grupo estavam os pacientes que haviam apresentado apenas um ou nenhum episódio de hemartrose antes do início do tratamento. Eles haviam iniciado a profilaxia primária nos dois primeiros anos de vida. Nenhuma evidência de lesão articular instalada foi observada após seguimento desse grupo por 11,25 anos, em média. No segundo grupo a profilaxia pelos FAH havia iniciado entre 3 e 6 anos de idade. Os pacientes desse grupo, antes do início do estudo, haviam sofrido em média seis hemartroses mas não mostravam alterações ortopédicas e radiográficas, já instaladas, no início do estudo. Surpreendentemente, os mesmos indicadores articulares ortopédicos e radiográficos utilizados para a avaliação dos pacientes, após três anos em uso do tratamento profilático, mostraram deterioração nas articulações estudadas. O terceiro grupo era constituído de pacientes que já apresentavam considerável deterioração articular tendo sofrido mais de 10 hemartroses antes do início do tratamento. Após serem submetidos às doses profiláticas do $\mathrm{FAH}, \mathrm{O}$ número de hemartroses sofreu redução significante no primeiro e no segundo grupos. Entretanto, os pacientes do segundo e do terceiro grupos experimentaram pióra em ambos os escores avaliados. Essa evolução sugeria que os pacientes que já haviam sofrido mais de cinco hemartroses, antes do início do tratamento, continuavam a sofrer deterioração osteoarticular. Ao contrário, aqueles que haviam iniciado a 
profilaxia sem nunca ter sofrido hemartrose, ou tendo sofrido apenas um episódio, não apresentaram nenhuma deterioração articular ao final do tratamento. Esses autores concluíram que para evitar a deterioração articular, mesmo naqueles hemofílicos em uso de doses profiláticas dos FAH, era necessário evitar as hemartroses de repetição.

Outros estudos, igualmente realizados em países desenvolvidos, chegaram a conclusões semelhantes quanto à importância do tratamento profilático (TP) em pacientes jovens, portadores de hemofilias graves ou seja, com níveis de FAH no sangue menores que 1\%. (RODRIGUEZMERCHÁN, 1997; AZNAR et al., 2000).

Ademais, em estudos sócio-econômicos mesclados com avaliações de qualidade de vida, autores como MOLHO et al., 2000 ; SCHRAMM e BERGER, 2002, provaram que o custo benefício da profilaxia primária, mesmo em regimes terapêuticos diferentes, quando comparado com a clássica terapia de reposição nas crises hemorrágicas, mostrou-se superior. Um estudo multicêntrico, realizado em dezesseis centros de assistência a hemofílicos de dez países europeus, que preconizava a profilaxia pela reposição do $\mathrm{FAH}$ por meio de tratamento domiciliar desde a infância, constatou haver apenas $3,4 \%$ de desempregados entre os pacientes submetidos a essa modalidade terapêutica. Por outro lado, o grupo dos hemofílicos que recebeu tratamento pela reposição do FAH apenas nas crises, apresentou 14\% de desempregados (SZUCS et al., 1998).

Um estudo retrospectivo, mostrou que o TP das hemartroses pode levar a complicações como tromboflebites nos locais de infusão, 
provavelmente devido à alta osmolaridade dos concentrados do FVIII. Entretanto, os autores (aa.) não confirmaram os achados de outros aa. que sugeriam a ocorrência de contaminação bacteriana nos cateteres de infusão de pacientes com inibidor. Observaram que o TP foi usado com sucesso em pacientes com inibidor, taxando de anedotais alguns relatos de desenvolvimento de inibidor pelo uso de TP publicados previamente. Sugerem que nos pacientes em que esse distúrbio foi verificado, poderia ter ocorrido excessiva oferta do fator num curto período de TP, como antecedendo uma grande cirurgia, ou um vazamento do produto no tecido celular subcutâneo, que teria levado ao desenvolvimento do inibidor. Outra hipótese para o desenvolvimento de inibidor na profilaxia pelo $\mathrm{FAH}$ seria na substituição do fator de coagulação por algum novo tipo de produto, mais puro do que o que estava sendo utilizado. Esses aa. constataram também o menor custo-benefício do TP, mantendo taxas de fator baixas mas compatíveis com a coagulação, em comparação ao tratamento nas crises hemorrágicas (BATOROVA e MARTINOWITZ , 2002).

Entretanto, nem a instituição da profilaxia em idade precoce foi capaz, como demonstrado por KREUTZ et al., 1998, de eliminar a progressão da artropatia hemofílica e impedir a degeneração articular em alguns pacientes.

Em nosso país, mesmo nos centros mais evoluídos, o melhor que se consegue é o tratamento imediato no início das crises de hemorragias, através de doses domiciliares de urgência (DDU) dos FAH. Nos casos em que ocorrem sangramentos articulares de repetição de difícil controle, 
pode-se lançar mão da denominada profilaxia secundária. Porém, há estudos que afirmam que tanto a profilaxia secundária quanto a profilaxia primária, nos pacientes que já apresentaram muitas hemartroses, pouco ou nada adiantam para o controle da sinovite crônica e da instalação da artropatia hemofílica, culminando com a instalação de posturas viciosas e, em decorrência, de atrofias musculares (ALEDORT, et al.,1994 ; HEIM et al., 1997).

Apesar do advento do tratamento profilático com concentrados dos $\mathrm{FAH}$, vários países ainda não têm acesso nem à reposição dos fatores da coagulação nas crises. Em alguns isso ocorre por falta de conhecimento médico das doenças hemorrágicas, em outros por falta de identificação dos pacientes, em outros ainda por falta de pessoal de saúde especializado em realizar as infusões dos $\mathrm{FAH}$ e de prover educação aos pacientes e seus familiares quanto aos cuidados necessários para evitar as hemorragias. Além disso, existe uma completa ausência de políticas de cuidados aos hemofílicos em um grande número de países em desenvolvimento (SRIVASTAVA et al., 1998).

Onde não seja possível a profilaxia primária, o tratamento mais favorável deve envolver uma combinação de reposição dos $\mathrm{FAH}$, repouso, crioterapia e reabilitação, supervisionada por especialistas (RIBANS et al, 1997).

Em adição à terapia de reposição, os tratamentos utilizados em nosso meio, na fase aguda das hemartroses, são a crioterapia e o uso de órteses estáticas para imobilização temporária das articulações afetadas (BUZZARD,1997 ; BATTISTELLA, 1998a; QUEROL et al., 2002). Esses 
meios terapêuticos auxiliam no alívio das dores e reduzem o stress na cápsula sinovial, permitindo um alívio mais precoce do quadro doloroso.

Nas fases subaguda e crônica, pode-se utilizar as correntes eletroanalgésicas, os ultrasons, os exercícios e as órteses funcionais, (BUZZARD e HEIM, 1995 ; BATTISTELLA, 1998b) com isso melhorando o desempenho dos hemofílicos nas atividades da vida diária e nas atividades profissionais.

No caso específico do tornozelo, a repercussão das limitações funcionais é ainda maior. Os pacientes, para evitar as descargas de peso nos membros afetados, têm de lançar mão de dispositivos auxiliares, para poderem locomover-se (BATTISTELLA, 1998a; BATTISTELLA, 1998b; QUEROL et al., 2002), mantendo as mãos ocupadas.

Para as hemartroses de tornozelo, potencialmente capazes de levar à incapacidade funcional, era necessário encontrar uma forma de dar a esses pacientes condições funcionais articulares, sem que para isso fosse necessário recorrer ao TP pelos $\mathrm{FAH}$, ainda não aprovado pelas autoridades sanitárias brasileiras.

Afinal, a maioria dos pacientes submetidos a este estudo, já tinha sofrido vários episódios de hemartrose nos tornozelos e em outras articulações, mesmo os mais jovens. Alguns desses pacientes apresentavam altas taxas de absenteísmo escolar ou laboral por causa das dores, segundo seus responsáveis. Era imperioso fazer alguma coisa que lhes permitisse desempenhar suas atividades com maior conforto, menos dores e com menores riscos de hemartroses de repetição. A pergunta era "como proceder" ?. 
Uma revisão na literatura mostrou que, nos hemofílicos, as articulações instáveis são propensas a hemartroses com maior freqüência (HEIJNEN et al., 1997 ; BUZZARD e HEIM, 1995 ; BUZZARD, 1998).

Assim, buscou-se um instrumento capaz de registrar a ocorrência de instabilidades articulares nos tornozelos e nos retropés. O método encontrado é capaz de fornecer dados quantitativos sobre a distribuição das pressões que incidem na superfície plantar durante a marcha e de constatar, de modo qualitativo, a presença de instabilidades dos tornozelos e dos retropés à marcha. Esse método foi a avaliação pela podobarometria dinâmica computadorizada.

Durante o exame, os pacientes caminham com sensores de pressão especiais colocados no interior dos calçados e ligados a um computador por fios coaxiais. O computador dispõe de um "software", que registra as pressões exercidas pelo solo nas superfícies plantares, durante a fase de apoio da marcha. O "software" permite avaliar dinamicamente essas pressões.

Um dos recursos desse programa consiste em registrar a maior pressão exercida em cada ponto da superfície plantar, desde o Toque do Calcâneo ("Heel Strike"), no início da Fase de Apoio, até o início da Fase de Balanço ("Toe off”) da marcha.

Esses pontos de maior pressão são reunidos pelo F-scan e formam a linha denominada Trajetória do Centro de Força (TCF), que nada mais é do que a somatória dos picos de pressão, verificados na superfície plantar, em cada instante da Fase de Apoio (SCHERER e SOBIESK, 1994). 
O estudo da distribuição das forças desenvolvidas entre o pé e o solo durante a marcha, bem como a determinação da Trajetória do Centro de Pressão, passo a passo, podem constituir instrumentos para determinação das instabilidades nas extremidades inferiores e do sentido dos desvios articulares (ROSE et al., 1992 ; HUGHES, 1993 ; JORGE FILHO et al., 2001). 


\section{OBJETIVOS}

A hemofilia é uma doença potencialmente incapacitante podendo, precocemente, levar à invalidez

A articulação do tornozelo é freqüentemente acometida e as manifestações clínicas são de difícil mensuração.

Assim sendo, este estudo teve como ob jetivos:

$>$ Definir uma metodologia para o diagnóstico funcional que permita, com segurança, constatar a ocorrência de instabilidades nos tornozelos e nos retropés, e avaliar o impacto da utilização de órteses no controle das hemartroses de repetição dos hemofílicos;

Avaliar a eficácia das órteses funcionais de tornozelo no controle das hemartroses e na redução do consumo dos fatores anti-hemofílicos 


\section{Hipóteses deste estudo}

A hipótese experimental do presente estudo foi que "a avaliação pela podobarometria dinâmica computadorizada colabora efetivamente para reduzir, nos hemofilicos, a ocorrência de hemartroses espontâneas"

A hipótese nula foi que "a avaliação pela podobarometria dinâmica computadorizada não colabora para reduzir a ocorrência de hemartroses espontâneas nos hemofílicos"

\section{Determinação do tamanho da amostra}

Para se determinar o Tamanho da Amostra, foi feita a comparação dos dados de consumo dos $\mathrm{FAH}$, objetivando-se estabelecer a proporção de sucesso na redução do consumo desses hemoderivados.

Procurou-se determinar o "poder do estudo", através da fórmula

Poder do Estudo $=1$ - erro beta

O erro beta adotado foi de $20 \%$. Desse modo o poder do estudo foi estabelecido em $80 \%$.

Como o estudo comparou dados contínuos, no caso o Consumo de Fatores Anti- Hemofílicos (FAH) antes e depois de uma intervenção clínica num mesmo grupo de pacientes, em um período de seis meses de 
observação, optou-se por aplicar o Teste "t" de Student Emparelhado, à média das diferenças.

Estabeleceu-se, para a análise comparada das duas médias pelo Teste $T$ Emparelhado, o valor de alfa $=0,05$, que é o nível de significância convencionalmente adotado para trabalhos médicos (JEKEL et al, 2002).

Feito o cálculo, verificou-se que para que o Poder do Estudo fosse $80 \%$, seria necessário avaliar 25 pacientes. 


\section{CASUÍSTICA E MÉTODOS}

\subsection{Casuística}

Foram estudados 43 pacientes hemofílicos, do sexo masculino, sendo 39 com hemofilia A e 04 com hemofilia B.

Os pacientes vieram encaminhados de cinco instituições:

Hospital Brigadeiro de São Paulo;

> Fundação Pró Sangue do Hospital das Clínicas da USP

> Hospital São Paulo, da UNIFESP

$>$ Centro de Hematologia de São Paulo

$>$ Centro Infantil de Investigações Hematológicas Dr.

Domingos A. Boldrini, de Campinas.

As idades desses pacientes variaram de 05 a 58 anos, com média de 16,1 anos (Gráfico 1).

Gráfico 1 - histograma representativo do número de pacientes submetidos ao estudo e respectivas faixas etárias

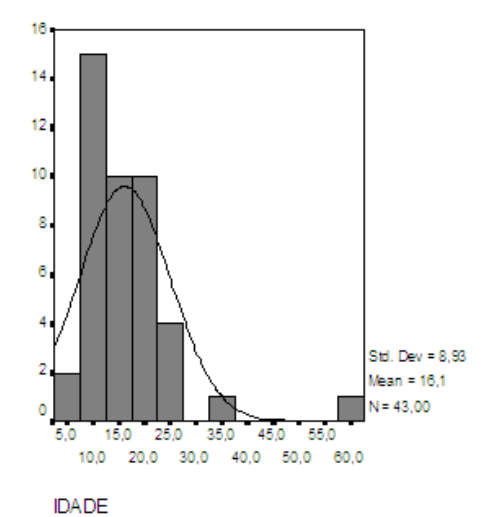

Além da faixa etária dos pacientes a análise da casuística envolveu a percepção de lateralidade de cada paciente e a gravidade da patologia. 
A lateralidade foi pesquisada rolando-se uma bola de borracha para que o paciente a devolvesse para nós com a face medial do pé. Consideramos como lateralidade preferencial para as atividades motoras o pé utilizado para essa função. Dentre os 43 pacientes com hemartroses de repetição nos tornozelos avaliados, 31 apresentaram lateralidade direita e12 tinham lateralidade esquerda.

Nos hemocentros de origem, de acordo com os níveis dos $\mathrm{FAH}$ no sangue circulante, os pacientes tinham sido classificados em:

hemofilia leve (6 pacientes) ;

$>$ hemofilia moderada (15 pacientes) ;

$>$ hemofilia grave (22 pacientes).

A maioria dos pacientes deste estudo havia sofrido várias hemorragias articulares, sendo que aquelas ocorridas nos tornozelos superavam, em número, as das demais articulações citadas como de maior sensibilidade às hemartroses (Tabela 1).

Tabela 1 - Número de hemartroses apresentadas pelos 43 pacientes estudados, nas três articulações mais freqüentemente acometidas por hemorragias, conforme a gravidade do acometimento, com base nas taxas de ocorrência dos FAH no sangue circulante

\begin{tabular}{cccccccccc}
\hline $\begin{array}{c}\text { HEMOFILIA } \\
\text { (GRAU) }\end{array}$ & \multicolumn{2}{c}{ TORNOZELO } & \multicolumn{2}{c}{ JOELHO } & \multicolumn{2}{c}{ COTOVELO } \\
\hline & DIR & ESQ & AMBOS & DIR & ESQ & AMBOS & DIR & ESQ & AMBOS \\
\hline LEVE & 17 & 3 & 0 & 9 & 8 & 0 & 0 & 0 & 0 \\
MODERADA & 38 & 40 & 3 & 7 & 6 & 0 & 13 & 11 & 0 \\
GRAVE & 54 & 49 & 3 & 13 & 6 & 1 & 24 & 54 & 1 \\
TOTAL & 109 & 92 & 6 & 29 & 20 & 1 & 37 & 65 & 1 \\
\hline
\end{tabular}


Antes da efetiva realização da pesquisa, o projeto foi apresentado à Comissão de Ética Para Análise de Projetos de Pesquisa - CAPPesq, do Hospital das Clínicas e da Faculdade de Medicina da Universidade de São Paulo, que autorizou a realização do estudo (ANEXO A).

Os dados obtidos no estudo foram coletados em planilhas que permitiram a comparação das condições pré e pós intervenção. As informações coletadas nas planilhas diziam respeito ao tipo e ao grau de hemofilia, ao membro inferior preferencial (destro ou sinistro), ao número e localização das hemartroses ocorridas e aos totais de unidades de FAH consumidos por paciente, por ocasião das hemartroses nos tornozelos, antes e depois da intervenção (ANEXO B)

\section{Critérios de inclusão na pesquisa}

Foram admitidos todos os pacientes que apresentavam, ao exame clínico e funcional, alterações menores em decorrência de sangramentos articulares anteriores, mas que tinham plena capacidade de deambular, sem necessidade de utilizar dispositivos auxiliares da locomoção.

\section{Critérios de exclusão}

$>$ Pacientes que tivessem limitações acentuadas nas amplitudes de movimento quer do tornozelo quer do retropé, ou que tivessem calosidades ou ulcerações sugestivas de grandes distúrbios funcionais nos pés; 
Igualmente os que apresentaram, ao exame clínico, limitações motoras estruturadas nas articulações dos membros inferiores, necessitando utilizar, continuamente, órteses ou outros dispositivos auxiliares da locomoção, foram eliminados da pesquisa.

Todos os pacientes ou seus responsáveis legais, no caso dos menores, foram completamente inteirados dos objetivos da pesquisa e da métodologia a ser utilisada, tendo a seguir assinado o Termo de Consentimento Esclarecido, antes de se submeterem aos exames e de utilizarem as órteses (ANEXO C).

As palmilhas e calçados ortopédicos foram fornecidos conforme os critérios de dispensação de órteses, próteses e dispositivos auxiliares da locomoção da Divisão de Medicina de Reabilitação - DMR - do Hospital das Clínicas da Faculdade de Medicina da Universidade de São Paulo, onde foram realizadas as avaliações e onde os pacientes faziam programa de reabilitação.

Sempre que foi necessário o uso de estabilizadores funcionais de tornozelos utilizou-se o tipo Air Stirrup, marca Air Cast, USA. Esse tipo de órtese semi-rígida provê boa restrição dos movimentos de inversão e de eversão dos tornozelos, melhorando a estabilidade nessas articulações e, desse modo, contribuindo profilaticamente para evitar tensões à cápsula articular (CORDOVA et al., 2002 ; BUZZARD E HEIM, 1995) potencialmente geradoras de sinovite nos hemofílicos. Contribuem também para a resolução mais rápida das hemartroses de repetição em 
Tabela 2 - Identificação e idade dos pacientes estudados, tipo e gravidade da doença, número de hemartroses sofridas e total de $\mathrm{FAH}$ consumido, seis meses antes da avaliação pela podobarometria e da intervenção com órteses

\begin{tabular}{|c|c|c|c|c|c|c|c|c|c|}
\hline \multirow[t]{2}{*}{$\mathrm{N}^{\mathrm{O}}$} & \multirow[t]{2}{*}{$\begin{array}{l}\text { Nome } \\
\text { Paciente }\end{array}$} & \multirow[t]{2}{*}{$\begin{array}{l}\text { Idade } \\
\text { (anos) }\end{array}$} & \multirow[t]{2}{*}{$\begin{array}{l}\text { Hemofilia } \\
\text { (Grau) }\end{array}$} & \multicolumn{5}{|c|}{$\begin{array}{c}\text { Hem a r tros es to ornoz e I os } \\
(P r \text { é órtes es ) }\end{array}$} & \multirow[t]{2}{*}{$\begin{array}{l}\text { Consumo } \\
\text { FCD-Total } \\
\text { (UI) }\end{array}$} \\
\hline & & & & DIR & ESQ & $D+E$ & ESPONTÂNEAS & TRAUMÁTICAS & \\
\hline 1 & ACA & 10 & A-grave & 4 & 2 & 3 & 9 & & 11000 \\
\hline 2 & ADS & 21 & B-moder & & 10 & & 7 & 3 & 16500 \\
\hline 3 & ARL & 27 & A-leve & 4 & & & 4 & & 6000 \\
\hline 4 & ASL & 16 & A-leve & 3 & & & 1 & 2 & 4000 \\
\hline 5 & BBA & 14 & A-grave & 2 & 11 & & 12 & 1 & 18750 \\
\hline 6 & $\mathrm{BBL}$ & 18 & A-grave & 1 & 1 & & 1 & 1 & 2000 \\
\hline 7 & BCR & 9 & A-grave & 2 & 4 & & 5 & 1 & 9000 \\
\hline 8 & BIS & 58 & A-leve & 6 & 1 & & 5 & 2 & 30500 \\
\hline 9 & BKM & 19 & A-grave & 1 & & & 1 & & 2500 \\
\hline 10 & BLGL & 18 & A-moder. & 8 & & & 6 & 2 & 6750 \\
\hline 11 & $\mathrm{CAL}$ & 19 & A-moder & 2 & & & 2 & & 4000 \\
\hline 12 & CLS & 24 & A-leve & $\overline{1}$ & 2 & & 3 & & 3000 \\
\hline 13 & DAMS & 15 & A-grave & 10 & 4 & & 14 & & 19500 \\
\hline 14 & DAS & 8 & B-moder & 3 & 6 & 1 & 7 & 3 & 13500 \\
\hline 15 & DES & 10 & A-moder & 4 & 5 & & 7 & 2 & 12250 \\
\hline 16 & DGPFF & 10 & A-grave & 1 & 5 & & 5 & 1 & 6000 \\
\hline 17 & $\mathrm{EF}$ & 7 & A-grave & 1 & & & 1 & & 2000 \\
\hline 18 & EFP & 18 & A-grave & 1 & 5 & & 5 & 1 & 12500 \\
\hline 19 & ELS & 14 & A-grave & 3 & & & 3 & & 4500 \\
\hline 20 & EMLS & 11 & A-grave & & 2 & & 2 & & 3750 \\
\hline
\end{tabular}


conclusão

\begin{tabular}{|c|c|c|c|c|c|c|c|c|c|}
\hline \multirow[t]{2}{*}{0} & \multirow[t]{2}{*}{$\begin{array}{l}\text { Nome } \\
\text { Paciente }\end{array}$} & \multirow[t]{2}{*}{$\begin{array}{l}\text { Idade } \\
\text { (anos) }\end{array}$} & \multirow[t]{2}{*}{$\begin{array}{l}\text { Hemofilia } \\
\text { (Grau) }\end{array}$} & \multicolumn{5}{|c|}{$\begin{array}{c}\text { Hemartroses Tornoz e Ios } \\
(P r \text { é órteses) }\end{array}$} & \multirow{2}{*}{$\begin{array}{l}\text { Consumo } \\
\text { FCD-Tota } \\
\text { (UI) }\end{array}$} \\
\hline & & & & DIR & ESQ & $D+E$ & ESPONTÂNEAS & TRAUMÁTICAS & \\
\hline 21 & ERCS & 20 & A-leve & 1 & & & 1 & & 2000 \\
\hline 22 & FAM & 10 & A-moder. & 5 & 2 & & 7 & & 9000 \\
\hline 23 & FLS & 27 & A-leve & 1 & & & 1 & & 3000 \\
\hline 24 & FPR & 10 & A-moder & & 5 & & 4 & 1 & 5250 \\
\hline 25 & FV & 19 & A-grave & & 2 & & 2 & & 5750 \\
\hline 26 & GAR & 16 & A-moder & 5 & 3 & & 8 & & 20000 \\
\hline 27 & GDB & 12 & A-grave & 7 & 2 & & 9 & & 18250 \\
\hline 28 & GGNS & 10 & A-grave & 1 & 2 & & 2 & 1 & 3000 \\
\hline 29 & GJM & 15 & A-moder & 1 & & & 1 & & 1500 \\
\hline 30 & $\mathrm{IZ}$ & 12 & B-moder & 3 & 1 & & 3 & 1 & 9000 \\
\hline 31 & $\mathrm{JCN}$ & 33 & B-moder. & 2 & & & 1 & 1 & 3600 \\
\hline 32 & $\mathrm{JKLT}$ & 11 & A-grave & 2 & 1 & & 3 & & 4750 \\
\hline 33 & JRSA & 8 & A-grave & 3 & & & 3 & & 2000 \\
\hline 34 & LF & 21 & A-moder. & & 2 & & 2 & & 16000 \\
\hline 35 & LFA & 9 & A-grave & 2 & 2 & & 4 & & 6500 \\
\hline 36 & LRN & 14 & A-moder & 1 & 6 & 1 & 5 & 3 & 14500 \\
\hline 37 & MEL & 15 & A-grave & 2 & & & 1 & 1 & 4000 \\
\hline 38 & MMTT & 13 & A-grave & 5 & 4 & & 5 & 4 & 43500 \\
\hline 39 & RLY & 25 & A-moder & & & 1 & & 1 & 3000 \\
\hline 40 & RRM & 18 & A-grave & 2 & & & 2 & & 4500 \\
\hline 41 & RRO & 5 & A-grave & & 1 & & 1 & & 250 \\
\hline 42 & SBMF & 14 & A-grave & 4 & & & 4 & & 18000 \\
\hline \multirow[t]{2}{*}{43} & TLA & 9 & A-moder. & 5 & 1 & & 6 & & 7500 \\
\hline & & 16,09 & & 109 & 92 & 6 & 175 & 32 & 390.850 \\
\hline
\end{tabular}



articulações alvo, como no caso dos tornozelos dos pacientes submetidos a esta pesquisa, bem como na redução da gravidade dessas hemorragias segundo estudo realizado com pacientes hamofílicos por conceituadas equipes de reabilitação de hemofílicos (BUZZARD, 1997).

Esses dispositivos, ademais, oferecem estimulação proprioceptiva (MATTACOLA e DWYER, 2002) e, contribuem para a melhora do equilíbrio e do desempenho funcional na articulação (DENEGAR e MILLER, 2002), conforme observações realizadas após entorses de indivíduos não hemofílicos. Segundo esses autores, a órtese funcional modelo Air Stirrup provê uma contensão bastante eficaz da pronação do retropé quando comparada a outros dispositivos estabilizadores das articulações dos tornozelos.

\subsection{Método}

Foram feitas visitas aos serviços de hemofilia de cinco instituições hospitalares, onde foram coligidos dados referentes à gravidade da hemofilia, à ocorrência de hemartroses de tornozelos, se traumáticas ou espontâneas, à lateralidade dessas ocorrências e ao consumo de FAH em cada episódio hemorrágico. O resultado desse estudo prévio está na Tabela 2.

A seguir, todos os pacientes foram submetidos a avaliações clínicas e ao exame goniométrico, destinado a verificar a ocorrência de desvios dos calcâneos. Do exame clínico constaram a avaliação geral para verificar se havia restrições à utilização funcional das articulações

dos membros inferiores, aumentos de volume, claudicações durante à marcha, decorrentes de dores músculo-esqueléticas, ulcerações ou 
TABELA 2 FOLHA 21.doc 
calosidades dolorosas, passíveis de alterar os resultados da podobarometria dinâmica computadorizada.

Os pacientes foram posicionados em ortostatismo sobre uma mesa e foram submetidos a goniometria. Com um goniômetro manual, foi medido o ângulo formado pelos calcâneos e pela perpendicular à linha basal formada pelo plano horizontal da mesa (QUEROL-FUENTES et al.,2000).

Após a goniometria dos retropés, os pacientes foram sudivididos em três grupos. Aqueles que não apresentavam desvios dos calcâneos no plano frontal, foram considerados normais quanto ao alinhamento. Os que tinham desvios em eversão do calcâneo acima de $7^{\circ}$ foram considerados retropés valgos (Fig. 1) e os que apresentavam desvios em inversão acima de $7^{\circ}$ foram considerados retropés varos (VAES et al., 1998).

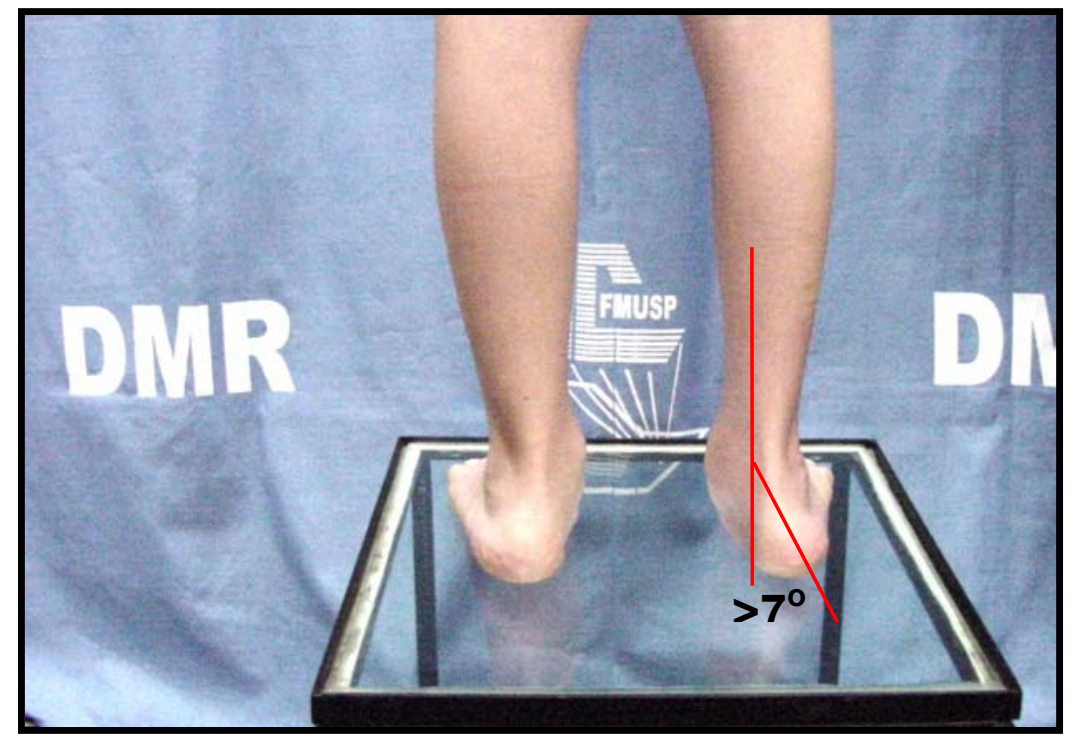

Fig. 1: podoscopia ortostática de paciente com retropés valgos, com ângulo $>7^{\circ}$

(VAES, 1998) 
A tabela 3 mostra a distribuição desses desvios nos retropés dos 43 pacientes que concluíram todas as etapas da pesquisa, agrupados segundo a faixa etária.

Tabela 3 - Alterações no alinhamento dos retropés dos hemofílicos, em ortostatismo

\begin{tabular}{|c|ccc|}
\hline & \multicolumn{4}{c|}{ DISFUNÇÃO OBSERVADA } \\
\hline IDADE & $\begin{array}{c}\text { RETROPÉS } \\
\text { NORMAIS }\end{array}$ & $\begin{array}{c}\text { RETROPÉS } \\
\text { VAROS }\end{array}$ & $\begin{array}{c}\text { RETROPÉS } \\
\text { VALGOS }\end{array}$ \\
\hline 0 a 10 & 4 & 5 & 4 \\
11 a 20 & 13 & 6 & 3 \\
$>21$ & 2 & 3 & 3 \\
\hline TOTAL & 19 & 14 & 10 \\
\hline
\end{tabular}

\section{Considerações sobre a podobarometria computadorizada}

Um meio complementar à avaliacçao clínica é o exame denominado podobarometria dinâmica computadorizada.

No presente estudo foi utilizado um podobarometro computadorizado modelo F-scan 4.11, que registra as pressões exercidas pelo pés contra o solo durante a Fase de Apoio da marcha (MUELLER \& STRUBE, 1996) e permite visualizar esses registros em movimento e em tempo real.

A podobarometria computadorizada é um sistema completo, composto de componentes de "software" e de "hardware".

Os componentes de "hardware" coletam dados da pressão plantar pelos sensores periféricos e disponibilizam essa informação para o "software". 
Cada sensor é continuamente amostrado até 165 vezes por segundo enquanto o paciente caminha. O "software" permite visualizar os dados de pressão coletados pelo sensor em tempo real, enquanto o paciente caminha, gravando essa informação como um filme, para revê-la e analisá-la posteriormente. Os componentes de "hardware" são:

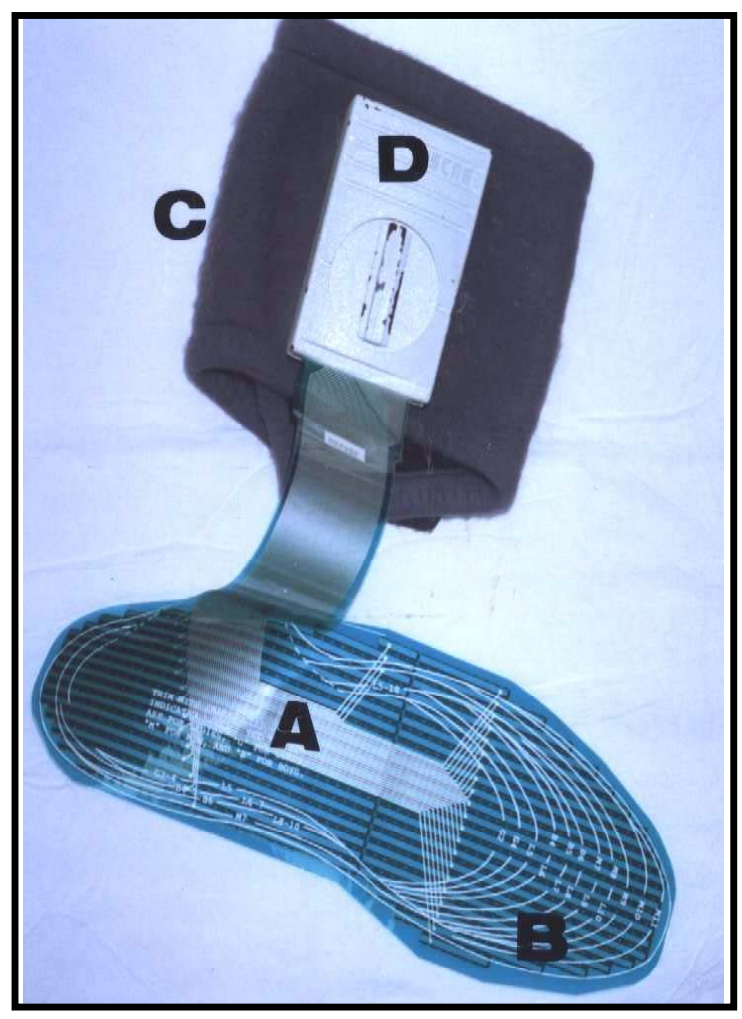

Fig. 2 - Componentes periféricos de "hardware" do F-scan :

(A) Sensor periférico, tipo palmilha, no tamanho original ;

(B) Linhas de corte para adequar as palmilhas aos calçados ;

(C) Perneiras para fixar os "cuff" ao tornozelo do paciente ;

(D) "Cuff" = Recebe os registros da pressão originados nas palmilhas, transcodifica-os e os envia para o "software".

sensores periféricos tipo palmilhas, com 0,18 mm, para inserir dentro dos calçados. Cada sensor tem 960 células sensíveis à pressão distribuídas por toda a sua superfície, para registrar as pressões exercidas pelas superfícies plantares dos pés contra o solo (Fig.2); 
unidades "cuff" de captação, processamento e transmissão dos sinais gerados pelos sensores de pressão localizados nas palmilhas;

perneiras de feltro para fixar os "cuffs" (Fig. 3-A);

fios coaxiais que levam os dados coletados a uma placa de interface conectada ao PC (Fig. 3-B);

cinto para fixação dos fios à cintura do paciente.

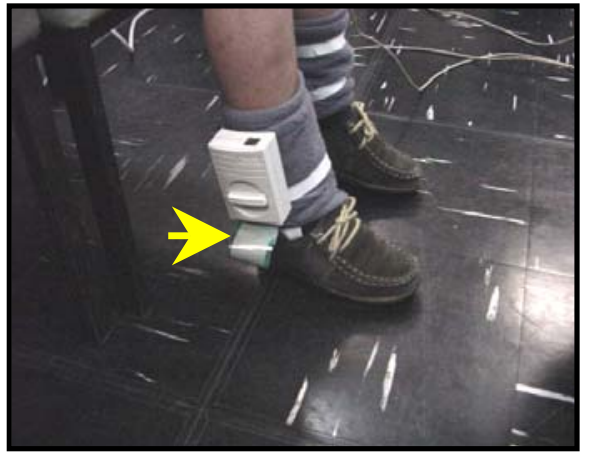

Fig. 3A: sensor tipo palmilha ligado ao "cuff"

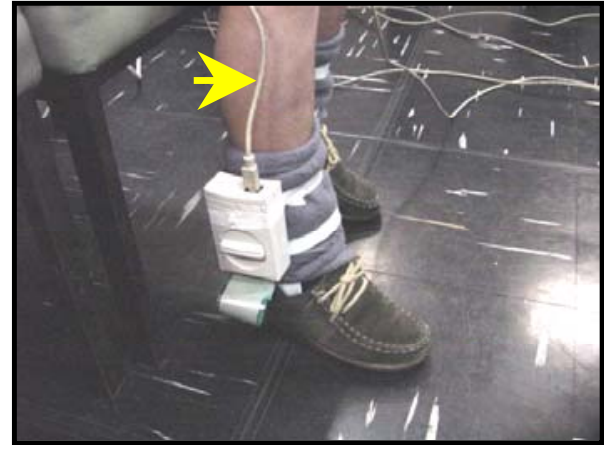

Fig. 3B: fio coaxial que vai do "cuff" ao PC.

A placa de interface conectada ao PC permite ao sistema adquirir os dados de pressão dos sensores e disponibilizá-los para o "software" do sistema. É inserida em um adaptador de expansão extra-computador, que pode ser levado para exames extra-laboratório. Os cabos coaxiais são fixados em conectores na placa de interface. A palmilha dispõe de sensores de pressão que detectam as pressões geradas entre a base do calçado e a superfície plantar do paciente, durante a Fase de Apoio da marcha. As células são arranjadas em linhas e colunas na palmilha. Cada célula pode ser vista como um quadrado individual na tela do computador, se selecionado o modo de exibição digital 2D. O software usa um mapa para converter a pressão detectada pelo "hardware" em dados de pressão exibidos na janela de tempo real. O sensor da palmilha é um 
circuito fino ultra flexível, virtualmente indetectável no calçado devido à sua espessura, e não interfere no caminhar normal do paciente. No tamanho original, cada palmilha pode ser utilizada por pessoas com pés de tamanho 14 americano. Para pessoas com pés menores os sensores são cortados com uma tesoura comum, em linhas demarcadas previamente, para que nenhuma célula restante seja inutilizada.

No presente estudo cada sensor foi utilizado sempre por um mesmo paciente, e no máximo seis vezes, sendo a seguir descartado.

Cada processador conecta-se com o sensor periférico por uma expansão da palmilha. O processador capta os dados do sensor periférico e os decodifica de modo que sejam facilmente enviados ao computador. A unidade processadora é fixada a um manguito que é preso com velcro em torno do tornozelo. Um cabo coaxial blindado leva as informações coletadas em cada unidade processadora para a placa de interface com o computador. Cada cabo tem 9 metros de comprimento, o que permite ao paciente andar livremente por 15 metros quando conectado ao sistema, desde que o computador esteja localizado no ponto médio da pista. Os cabos são fixados à cintura do paciente, por trás do corpo, para maximizar a liberdade de movimentos durante o teste.

O "software" utilizado pelo sistema é compatível com ambiente Windows. O podobarometro utilizado na pesquisa é capaz de processar os dados de pressão colhidos pelos sensores periféricos e apresentá-los em forma de gráficos, ou de quadros.

No presente estudo, a função usada para se verificar a presença das instabilidades dos tornozelos (articulação tíbio-társica) e dos retropés 
(articulação subtalar) foi a Trajetória do Centro de Pressão, determinando-Ihes as direções dos desvios durante a fase de apoio da marcha.

O Centro de Pressão - CP - mostra o centro de todas as forças, em tempo real, como um filme. A Trajetória do $\mathrm{CP}$ corresponde à linha determinada pelos pontos de maior pressão registrados em cada linha de sensores, à medida em que o paciente vai transferindo o peso do corpo para cima da superfície plantar do pé, desde o calcâneo até o antepé.

A TCP exibe o movimento do CP pela duração do filme gravado.

O uso dessa opção para rastrear o CP é essencial para estudar e analisar o modo de andar do paciente e a estabilidade das articulações tíbio-társica e subtalar, durante o ciclo da marcha.

Segundo GRUNDY et al., 1975, a TCP, num pé estável, inicia no retropé quando a porção plantar da Tuberosidade do Calcâneo toca o solo. Progride para a porção anterior do pé, quase reta pela linha média da superfície plantar, mais próxima da borda medial do que da borda lateral do pé. Finalmente, ao atingir o antepé, o CP permanece sob as cabeças metatarsianas mesmo depois que os dedos já estão em total contato com o solo (Fig.4) .

Fig. 4: TCP em um pé estável: Na observação "passo a passo", observa-se leve instabilidade medial, verificada pelo desvio medial na trajetória do primeiro passo gravado.

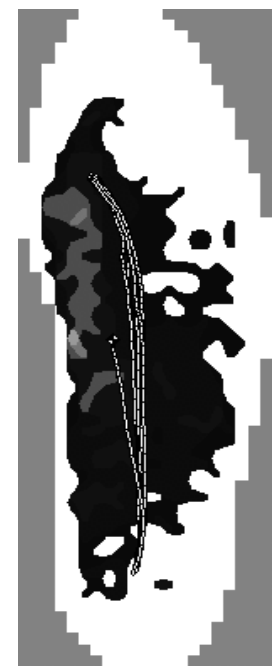




\section{Podobarometria nas hemartroses dos tornozelos}

Os pacientes que compareceram para exame com dores músculoarticulares tiveram seus exames adiados para não haver interferência nas características da marcha. Nenhum paciente sofreu restrições nas atividades habituais durante a pesquisa. Todas as avaliações foram realizadas no mesmo local, a uma temperatura estabilizada em $24^{\circ} \mathrm{C}$ e pressão em torno de $760 \mathrm{~mm}$ de mercúrio, em terreno plano e regular, seguindo sempre o mesmo trajeto. Os exames podobarométricos consistiram inicialmente da calibração do sistema (LI et al, 2000) fornecendo ao computador o peso dos pacientes, suportado em cada pé individualmente (Fig.5). Cada paciente percorreu a pista caminhando livremente e em velocidade confortável, durante 3 minutos, para adaptarse aos dispositivos do sistema e para padronizar a cadência da marcha (Fig.6).

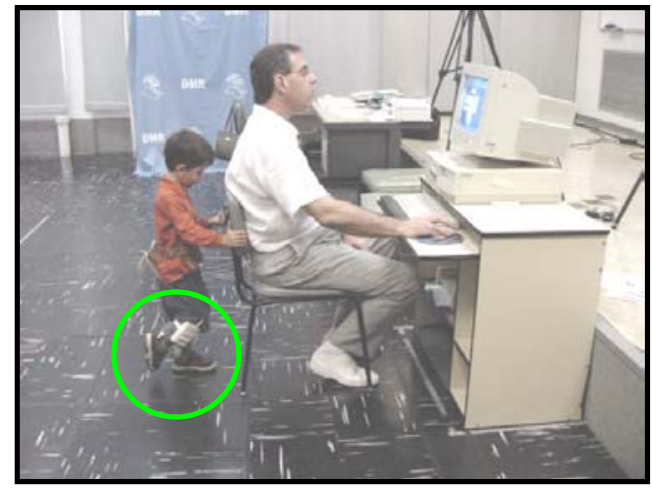

Fig. 5: calibração do aparelho

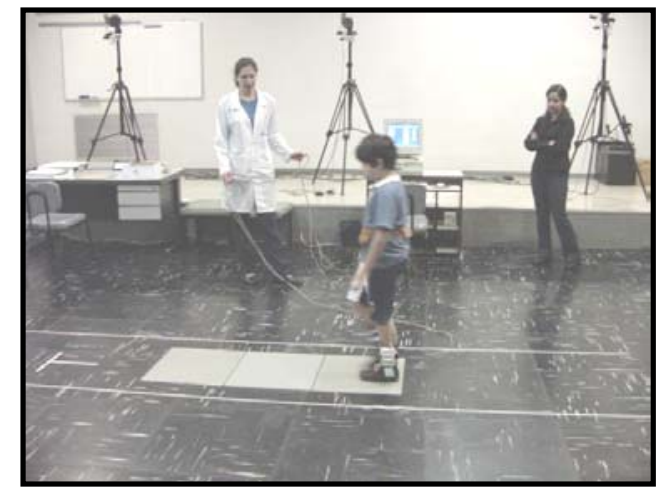

Fig. 6: definição da cadência

Depois, sem aviso prévio, foram gravados passos para a frente em linha reta, durante oito segundos, com os pacientes de costas para a tela 
do computador. Foram refeitas as gravações sempre que os pacientes saíram do trajeto pré estabelecido. Evitou-se gravar curvas ou meiasvoltas assim como gravar com os pacientes olhando para a tela do computador. Desse modo pôde-se evitar que o estímulo visual ou as meias-voltas do corpo interferissem, no padrão da marcha.

Os pacientes foram submetidos a pelo menos três avaliações. A primeira, antes de começarem a usar as órteses. A segunda, uma semana após iniciarem o uso das órteses e a terceira, após seis meses de sua efetiva utilização.

Os dois primeiros meses após a realização do exame podobarométrico foram utilizados para o fornecimento e adaptação das órteses e para as correções de alinhamento articular dos pacientes. Os seis meses seguintes é que foram considerados na avaliação da eficácia das órteses.

\section{Confecção e Adaptação das Órteses}

Para definir as compensações a serem incluídas nas palmilhas e sua localização procedeu-se como segue: palparam-se com os dedos as cabeças dos ossos metatarsianos, que foram marcadas com "baton" ou com "pincel atômico", nos dois pés (A). A seguir, os pacientes pisaram sobre uma folha de papel branco imprimindo nela as cabeças metatarsianas (B). Riscaram-se os contornos dos pés com uma caneta escura, assinalando-se também as extremidades anterior e posterior dos arcos plantares mediais (C). Quando o paciente retirava os pés das folhas de papel estavam completos os moldes plantares em tamanho natural, já 
localizadas as cabeças dos metatarsianos e os arcos mediais (D). A partir desses moldes foram confeccionadas as palmilhas (E) (Fig. 7- A a E).
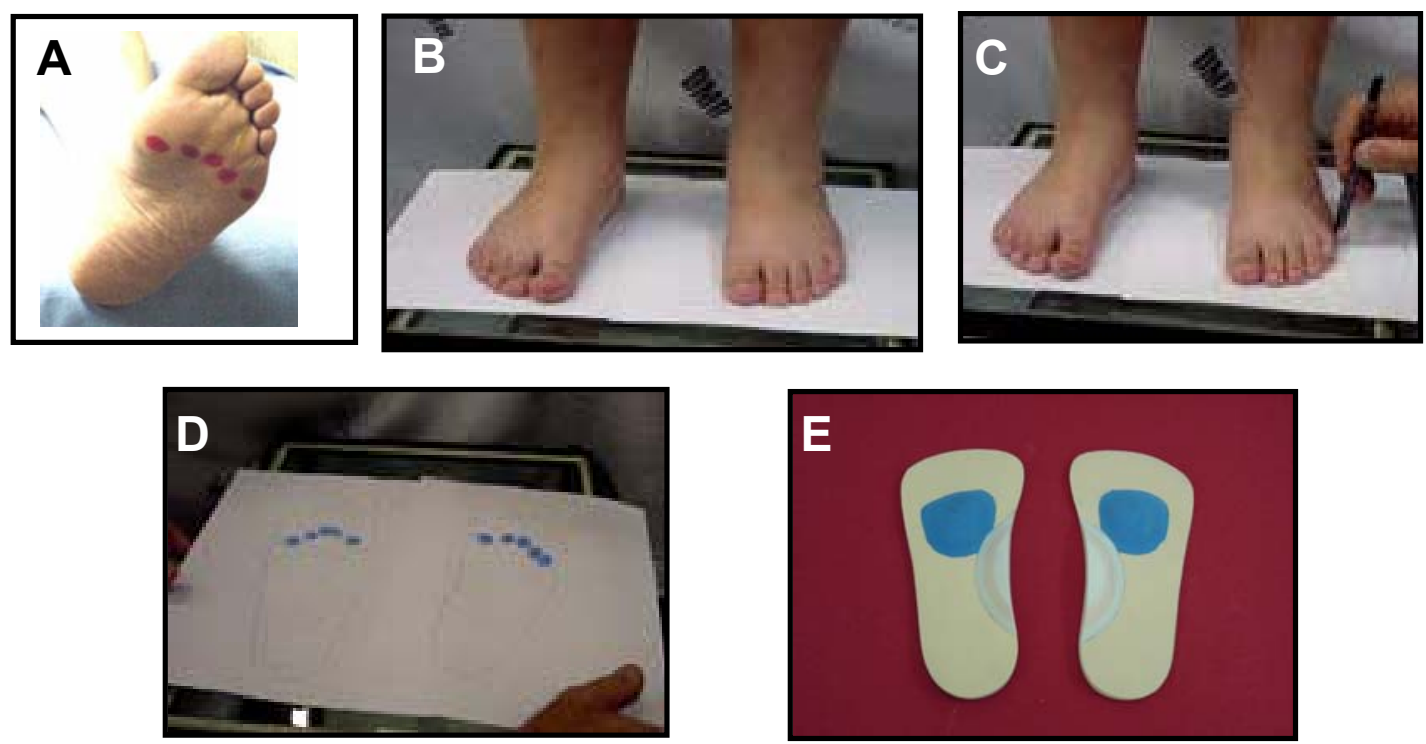

Fig. 7: técnica de confecção das órteses plantares

Para pés cavos ou com pressões excessivas nas cabeças dos metatarsianos centrais, sugerindo retificação do arco plantar anterior, foram colocadas almofadas metatarsianas $5 \mathrm{~mm}$ atrás das cabeças dos primeiro, segundo e terceiro metatarsianos.

Essas almofadas elevando as diáfises dos ossos centrais do metatarso, objetivavam a recomposição do arco transverso do antepé.

Nos pacientes com desvio do retropé lateralmente - TCP desviada para o bordo lateral do pé - elevou-se o retropé com uma cunha de base lateral (Fig.8-A,B,C). 


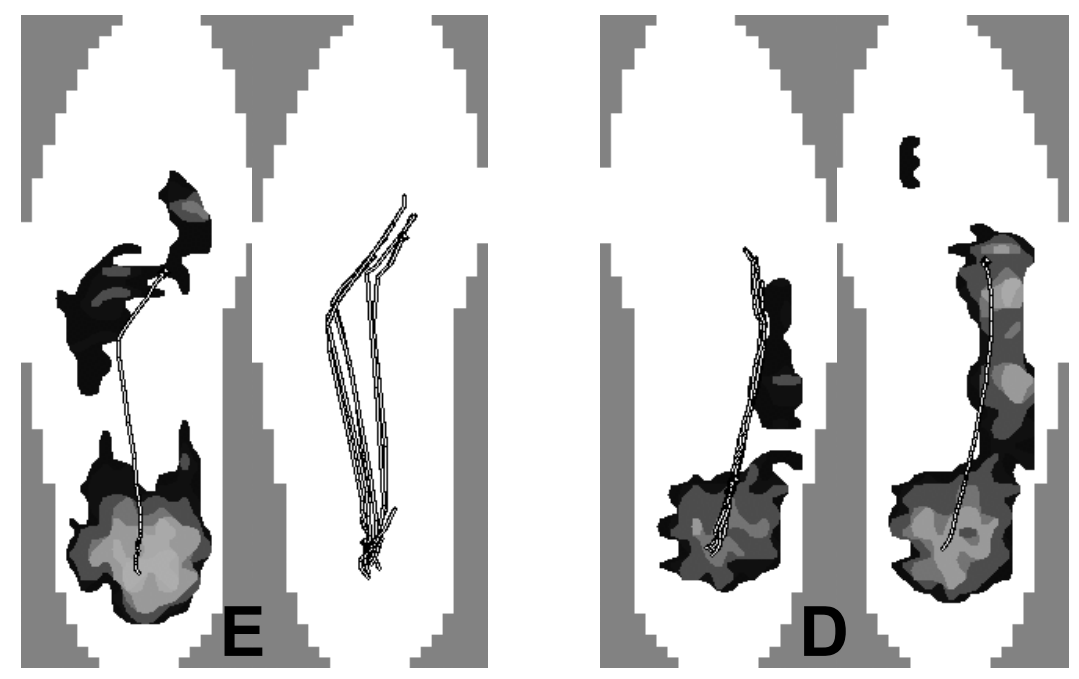

Fig.8A: Pé esquerdo cavo-varo-aduzido instável :

(E) Linhas da TCP divergentes, com desvio lateral Pé direito cavo-varo-aduzido estável :

(D) Linhas da TCP convergentes com desvio lateral Em 06-06-01, sem palmilhas.

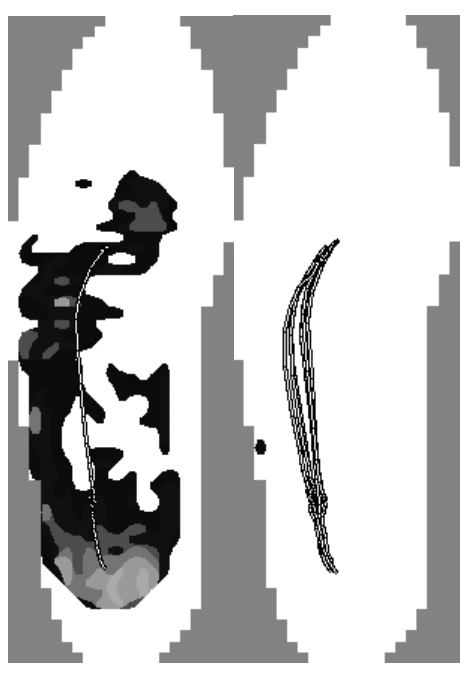

Fig.8B: Utilizando uma palmilha com elevação da borda lateral do retropé.TCP mais convergente. 08-08-01

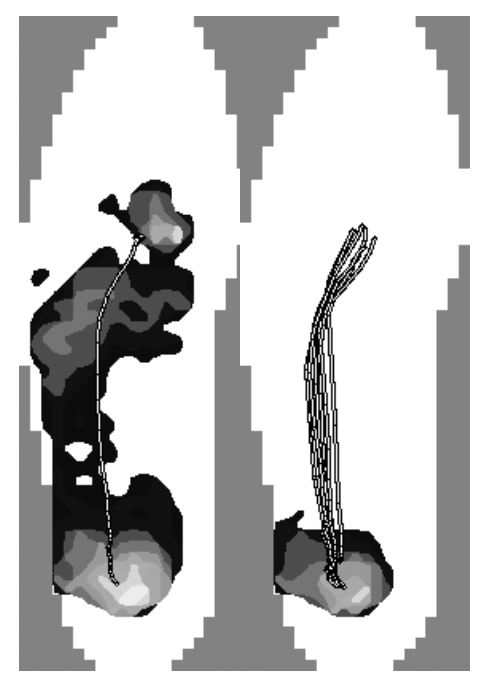

Fig.8C: Palmilhas + Air Stirrup TCP convergente e centralizada TCP chegando à polpa do hálux. 15-08-01 
Por outro lado, naqueles em que a podobarometria mostrava desvio medial da TCP, foi colocada uma cunha elevando o bordo medial do retropé.

Nos pés planos ou valgos graves, a TCP era desviada acentuadamente para o bordo medial do pé. A instabilidade do retropé que causa esse desvio faz com que as linhas correspondentes à TCP em cada passo fiquem muito separadas umas das outras (Fig.9A). Nesses casos fez-se a elevação de todo o bordo medial e ainda um suporte para o arco plantar medial, com evidente estabilização da TCP (Fig. 9B).
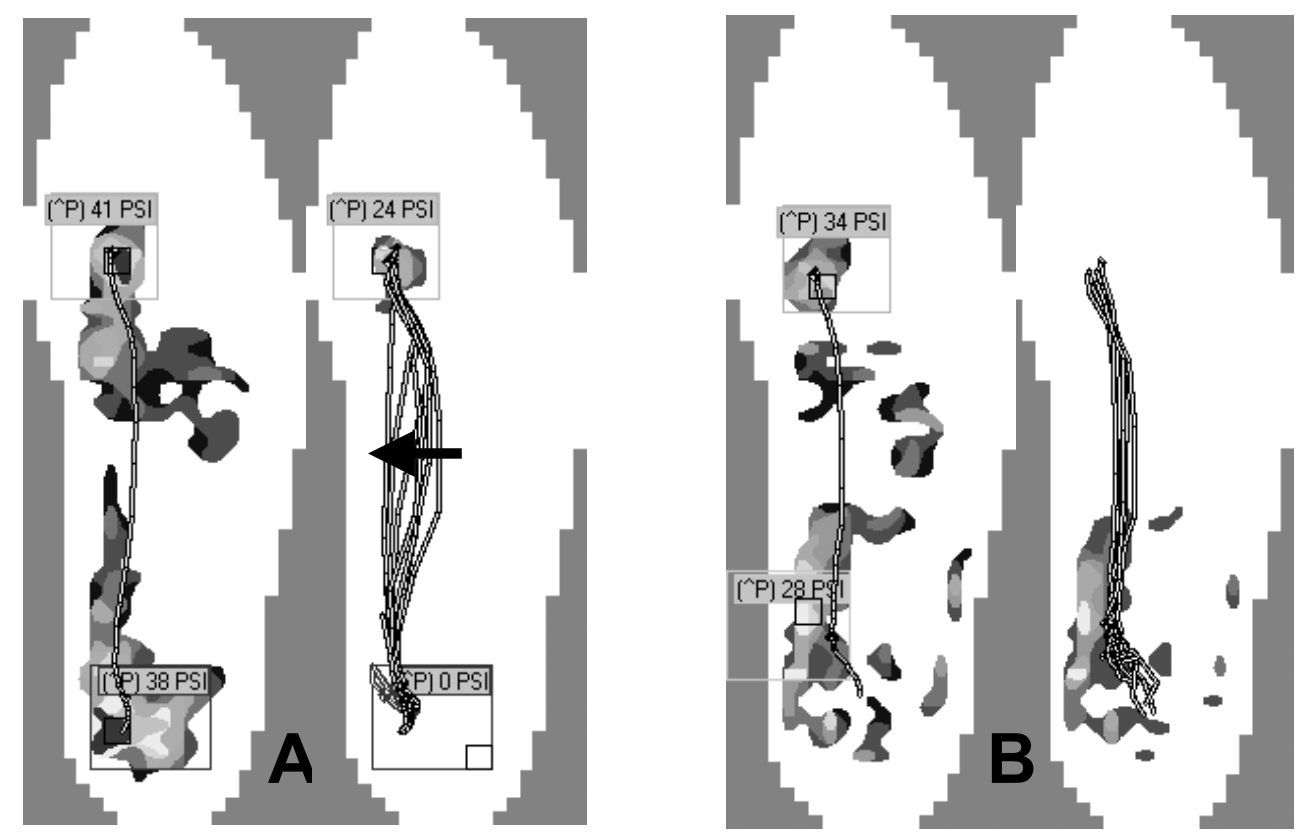

Fig. 9 - TCP em um Pé Direito Plano-valgo grave :

(A) Sem palmilha:

Linhas divergentes. Desvio para a borda medial do pé $(\longleftarrow)$; Aumento de pressão no halux e na borda medial do retropé.

(B) Palmilha elevando borda medial do retropé e arco medial:

Linhas convergentes e mais centralizadas na região plantar; Redução de pressão no hálux e na borda medial do retropé; Registram-se mais áreas de pressão na borda lateral do pé. 
Nos casos de valgismo muito acentuado do retropé, ou de frouxidão ligamentar importante, a podobarometria mostrava concentração de pressões na primeira articulação metatarso-falangeana. Alguns pés já mostravam um início de hálux valgus (Fig. 10A). Nesses casos foram indicadas almofadas sob as diáfises dos metatarsianos centrais e cunhas anti-valgo (ROSE et al,1992; HUGHES,1993) (Fig.10B).
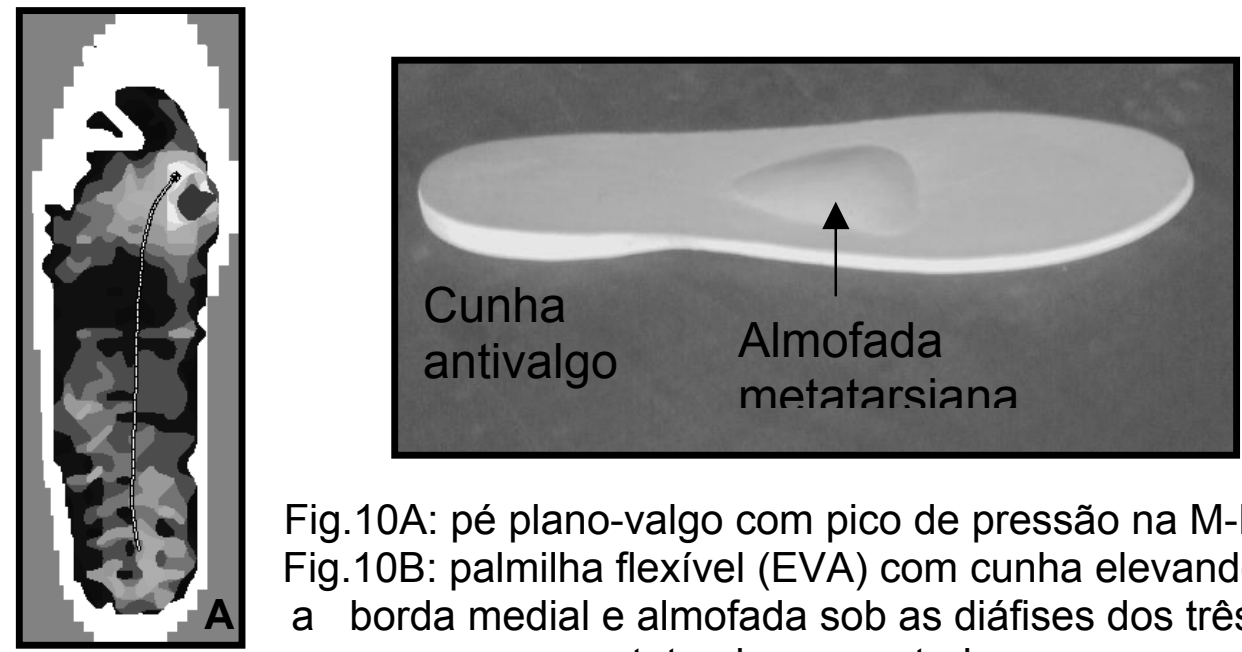

Fig.10A: pé plano-valgo com pico de pressão na M-F1; Fig.10B: palmilha flexível (EVA) com cunha elevando a borda medial e almofada sob as diáfises dos três metatarsianos centrais.

Em todos os pacientes nos quais não foi necessária a colocação de cunha em todo o bordo lateral ou medial as palmilhas foram feitas com 3/4 do comprimento dos pés. Com palmilhas mais curtas, pôde-se utilizar calçados com a numeração exata dos pacientes, já que calçados maiores do que o necessário trazem instabilidades aos pés. Para as palmilhas não se deslocarem para a frente dos calçados, alterando a localização das almofadas de apoio nas regiões plantares, foram colocadas tiras de velcro 
auto-adesivas no interior dos sapatos e na porção correspondente da face inferior das palmilhas (Fig. 11A,B )

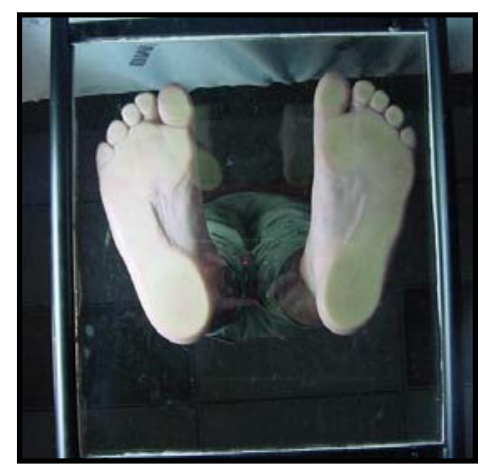

Fig. 11-A : retificação dos arcos anteriores e arcos mediais rasos sem desvios nos retropés

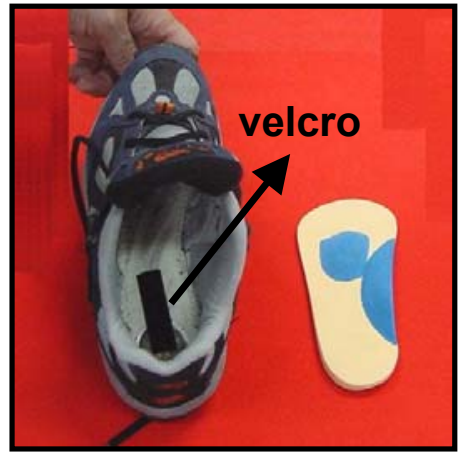

Fig. 11-B : palmilhas com 3/4 do comprimento dos pés e almofadas para os arcos retificados

As bases das palmilhas foram confeccionadas em Etil-vinil-acetato (EVA) ou em lamina de couro delgada, para permitir boa flexibilidade aos pés durante a marcha. As cunhas foram feitas com EVA ou Plastazote e as almofadas sob os arcos anterior e medial, em compostos de borracha.

Somente pacientes com grande instabilidade de tornozelo, devido fraqueza ligamentar, receberam estabilizadores desportivos de tornozelo além das palmilhas. No presente estudo, o estabilizador de tornozelo escolhido foi o modelo Air Stirrup (STOVER, 1980; MARSH e DAIGNEAULT, 2000; EILS et al., 2002; BUZZARD E HEIM, 1995). Essa órtese semi-rígida configurou boa estabilidade ao retropé, produzindo menor restrição aos movimentos de flexão dorsal e plantar. Sob esse aspecto, ela não difere da imobilização por enfaixamento com esparadrapo, que é citada como bastante eficaz nas instabilidades dos tornozelos (NISHIKAWA et al, 2000; MATSUSAKA et al., 2001). 
Tanto o enfaixamento como a órtese funcional modelo Air Stirrup, mostram-se capazes de contribuir de modo eficaz no controle das instabilidades (VAES et al., 1998). Avaliado pela podobarometria, um tipo de enfaixamento com esparadrapo se mostrou muito eficaz na restrição das instabilidades no plano frontal, causando pouca restrição das planti e dorsiflexões, e estabilizando a TCP. Entretanto, sua utilização não se viabilizou por ter causado alergias cutâneas aos pacientes e ter de ser refeita diariamente (Fig. $12 \mathrm{~A}$ a C).

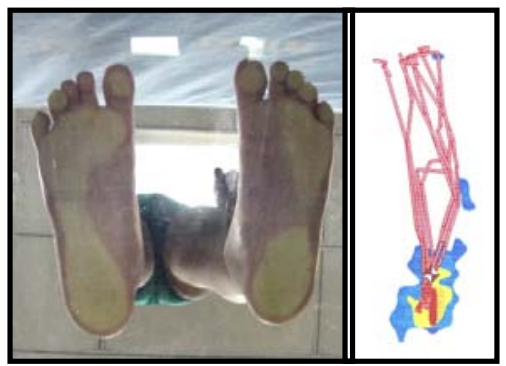

Fig.12A : pé cavo-varo e TCF antes do enfaixamento

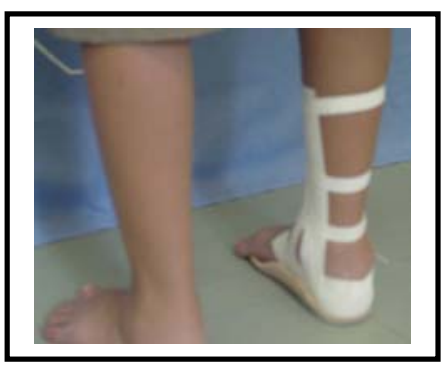

Fig.12B : detalhe do enfaixamento

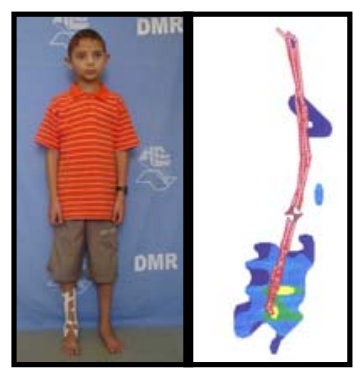

Fig.12C: TCF após o enfaixamento

\section{Variáveis Submetidas à Análise Estatística}

> Total de hemartroses sofridas pelos 43 pacientes submetidos a todas as fases do estudo, isto é, avaliados nos seis meses antes da realização da podobarometria dinâmica computadorizada e nos seis meses depois.

2. Totais de Unidades de FAH utilizados para coibir as hemartroses ocorridas no grupo de 43 pacientes submetidos a todas as fases do estudo, nos seis meses antes e nos seis meses depois da podobarometria computadorizada e da utilização das órteses. 


\section{Análise da Casuística}

Foram calculadas as médias aritméticas de todas as hemartroses, espontâneas e traumáticas, ocorridas nos tornozelos dos 43 pacientes, antes e depois da intervenção. Como as diferenças entre elas, apresentassem uma distribuição simétrica ao Teste $\mathrm{T}$ Emparelhado (Gráfico 2), foram calculadas as respectivas médias aritméticas e desvios padrão.

Gráfico 2 - Histogramas obtidos a partir da análise da freqüência de todas as hemartroses, espontâneas (esp) e traumáticas $(\mathrm{t})$, ocorridas nos tornozelos de 43 hemofílicos, nos seis meses pré-intervenção (preespt) e nos seis meses pós-intervenção (posespt), mostrando distribuição simétrica

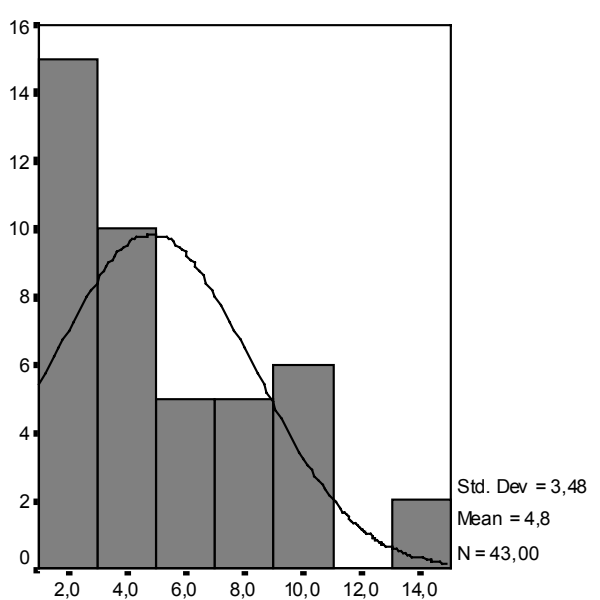

PREESPT

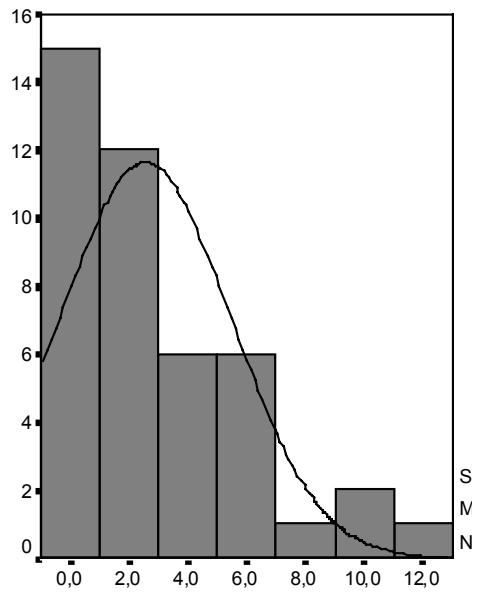

POSESPT

Os dados referentes ao número de hemartroses ocorridas nos tornozelos esquerdos dos 43 pacientes estudados mostraram distribuição assimétrica. O teste não paramétrico de Spearman aplicado a esses dados mostrou ser possível o emparelhamento entre eles. Foram então comparados pelas respectivas medianas, com base no Teste de Wilcoxon 
Signed Rank Sum, indicado para dados entre dois grupos emparelhados,(DORIA FILHO,2001; JEKEL et al.,2002) (Gráfico 3)

Gráfico 3 - Histogramas mostrando as hemartroses ocorridas nos tornozelos esquerdos (e) dos 43 pacientes estudados, antes (pree) e depois (pose) da intervenção, mostrando distribuições assimétricas

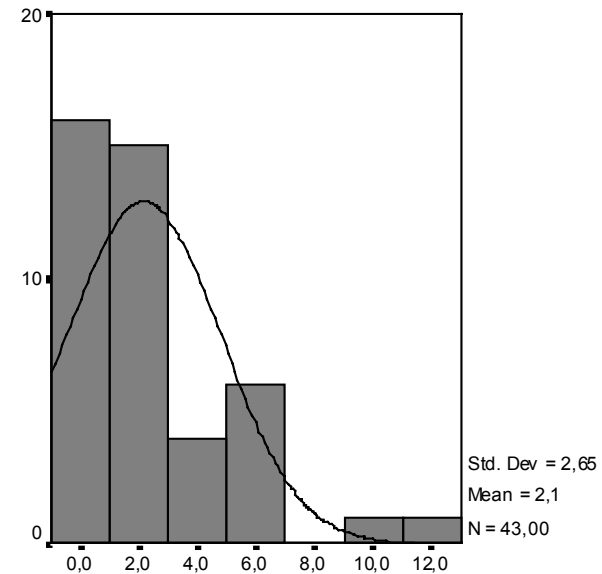

PREE

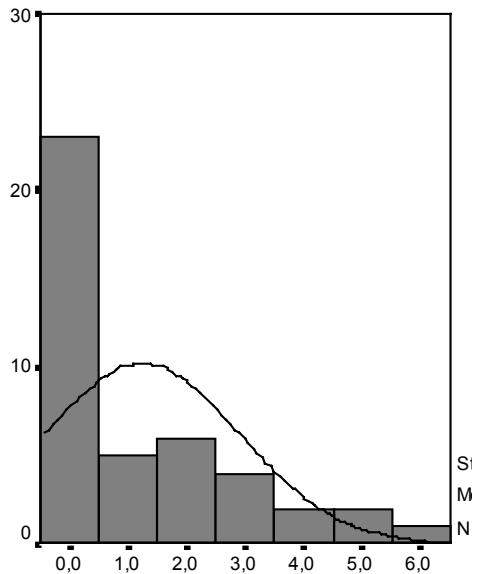

POSE

Analogamente, os dados referentes ao número de hemartroses ocorrido nos tornozelos direitos dos 43 pacientes estudados, antes e depois da intervenção, mostraram distribuição assimétrica. $O$ teste não paramétrico de Spearman aplicado a esses dados mostrou ser possível o emparelhamento entre eles. Assim foram também comparados pelo Teste de Wilcoxon Signed Rank Sum, aplicado às respectivas medianas (Gráfico 4) 
Gráfico 4 - Histogramas mostrando as hemartroses ocorridas nos tornozelos direitos (d) dos 43 pacientes estudados, antes (pred) e depois (posd) da intervenção, mostrando distribuições assimétricas

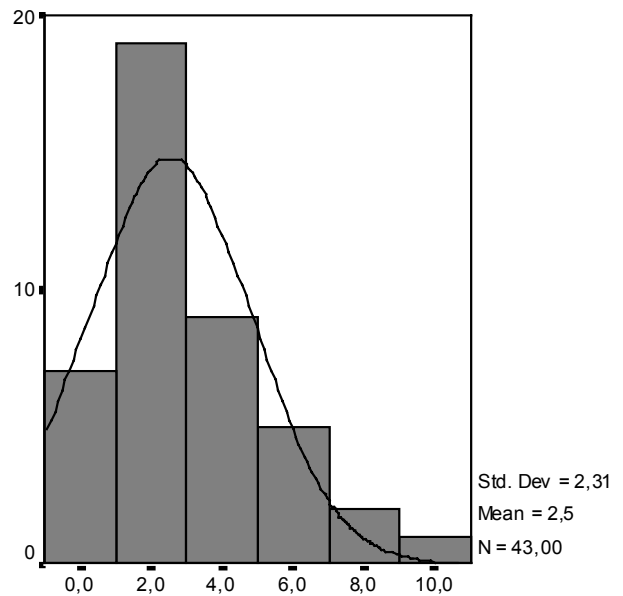

PRED

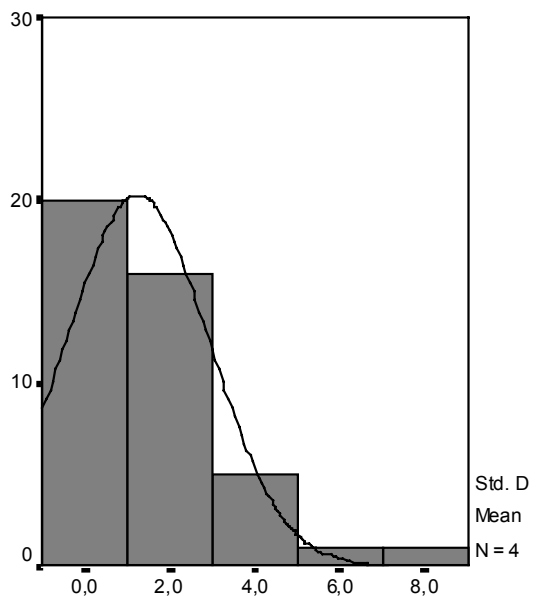

POSD

As hemartroses bilaterais foram analisadas pelo teste não paramétrico de Spearman e consideradas passíveis de emparelhamento.No entanto, por terem sido eventos esporádicos no transcorrer do estudo, suas medianas comparadas pelo Wilcoxon Signed Rank Sum resultaram pouco significantes $(P=0,125)$.

Outro estudo comparando o número de hemartroses unilaterais antes e depois da intervenção (307 ou 98\%) com o número de hemartroses bilaterais antes e depois da intervenção (7 ou 2\%) através do Teste Exato de Fischer, demonstrou que a comparação desses dados não era estatisticamente significante $(P=0,420)$, razão pela qual as 
hemartroses bilaterais não deverão ser consideradas no capítulo de resultados.

Os dados referentes às causas das hemartroses, classificados em espontâneas e traumáticas, de acordo com as informações colhidas nos prontuários das instituições de origem dos 43 pacientes submetidos ao estudo, também apresentaram uma distribuição assimétrica (Gráfico 5).

Gráfico 5 - Histogramas mostrando todas as hemartroses espontâneas (esp) ocorridas nos tornozelos dos 43 pacientes estudados, antes (preesp) e depois (posesp) da intervenção, mostrando distribuições assimétricas

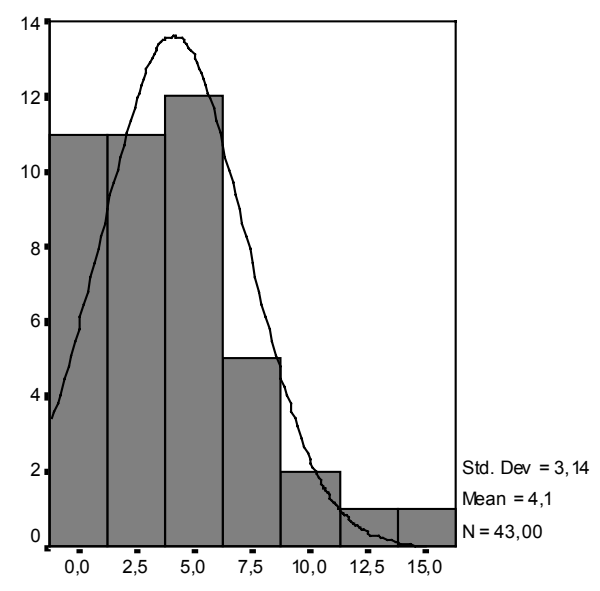

PREESP

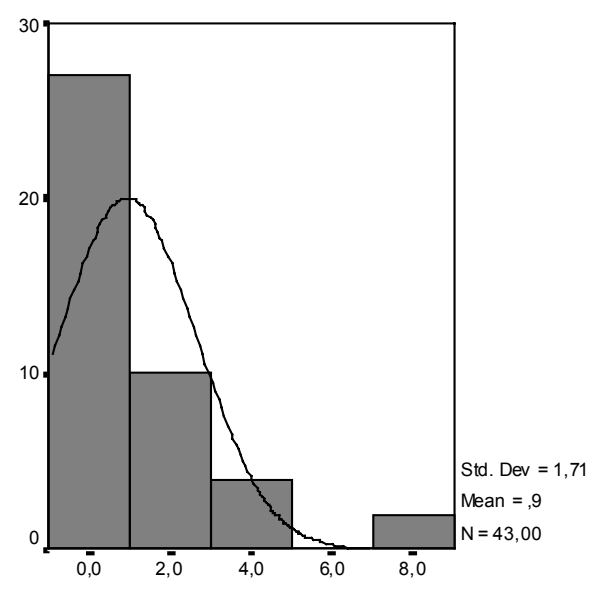

POSESP

Primeiramente, as hemartroses espontâneas foram correlacionadas através do teste não paramétrico de Spearman, que considerou possível o emparelhamento. Foram então comparadas as medianas através do teste de Wilcoxon Signed Rank Sum. 
Da mesma forma, a seguir, foram correlacionados os dados referentes às hemartroses traumáticas, que também apresentaram uma distribuição assimétrica. A correlação através do teste não paramétrico de Spearman, considerou possível o emparelhamento. Foram então comparadas as medianas através do teste de Wilcoxon Signed Rank Sum.

A diferença entre as médias do Consumo de Fator Anti Hemofílico necessário à recuperação das hemartroses sofridas foi feita pelas médias aritméticas pois sua distribuição ao Teste T Emparelhado obedecera uma distribuição simétrica. 


\section{RESULTADOS}

Antes da realização da intervenção diagnóstica e terapêutica nos 43 pacientes que concluíram o estudo, verificou-se que, de acordo com o lado afetado, 53\% ( $\mathrm{N}=109)$ das hemartroses haviam ocorrido no tornozelo direito, $44 \%(\mathrm{~N}=92)$ no tornozelo esquerdo e $3 \%(\mathrm{~N}=6)$ em ambos os tornozelos simultaneamente, totalizando 207 hemartroses em seis meses.

Após a intervenção a ocorrência de hemartroses foi de $50 \%(\mathrm{~N}=53)$ em cada tornozelo isoladamente e de $1 \%(\mathrm{~N}=1)$, em ambos os tornozelos simultaneamente, num total de 107 episódios hemorrágicos em seis meses.

Através da podobarometria computadorizada foi possível encontrar instabilidades nos tornozelos dos pacientes, bem como verificar a estabilização dessas articulações após se adaptarem às órteses, prescritas com base nos resultados obtidos no exame (Fig. 13).

No cálculo dos resultados obtidos pelo método empregado, foram coletados dados referentes a duas variáveis:

1. número de hemartroses ocorridas nos tornozelos dos pacientes

2. quantidades de fator da coagulação utilizadas no tratamento de cada episódio hemorrágico envolvendo os tornozelos.

Esses dados foram obtidos das anotações existentes nos prontuários médicos dos pacientes, nos centros de hemoterapia em que eles se encontravam registrados e onde eles receberam os tratamentos por reposição dos FAH. Foram revisadas as anotações dos prontuários nos seis meses que antecederam a avaliação podobarométrica e nos seis 
meses após a adaptação dos pacientes às órteses. Esses dois conjuntos de dados foram comparados para se chegar aos resultados da pesquisa.

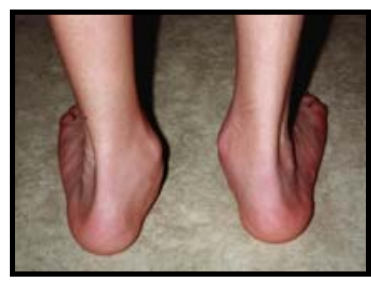

A: pés valgos instáveis
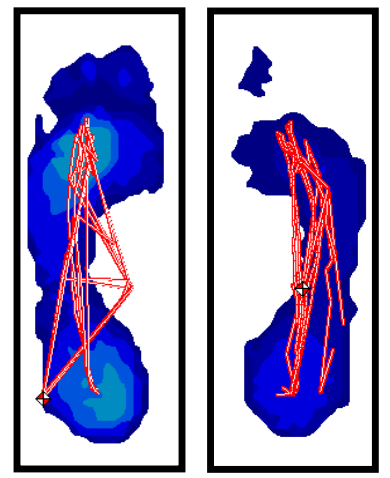

A1: trajetória do centro de pressão pré intervenção

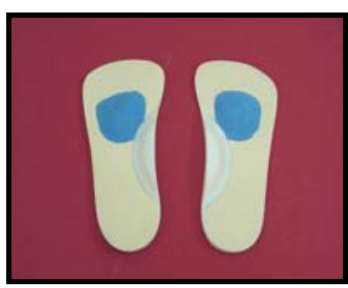

B: palmilhas para estabilização

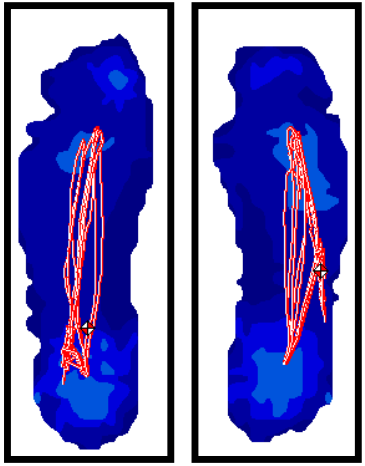

B1: trajetória do centro de pressão usando palmilhas

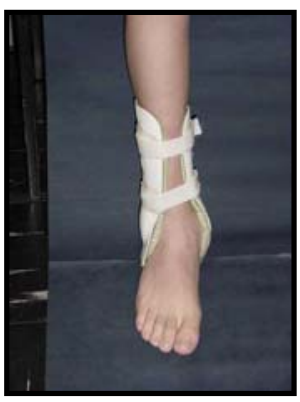

C: Air Stirrup

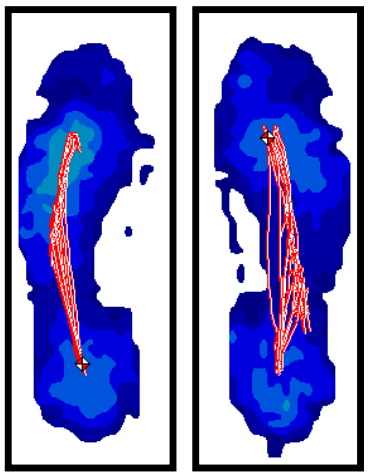

C1: trajetória do centro de pressão com palmilhas + Air Stirrup

Fig. $13 \mathrm{~A}$ a C1: estudo evolutivo da TCP em um paciente com retropés valgos, pré e pós adaptação às órteses. A estabilidade crescente é demonstrada pela aproximação entre as linhas da TCP, passo a passo

$\mathrm{Na}$ tabela 4 são apresentados Identificação dos pacientes, tipo e gravidade da hemofilia, número de hemartroses e total de fator antihemofílico consumido, comparando-se os dois períodos de avaliação, pré e pós intervenção com órteses. 
Tabela 4: Identificação, idade, tipo e gravidade da doença, número de hemartroses e total de fator de coagulação consumido. Comparação dos seis meses antes com os seis meses depois da intervenção com órteses

\begin{tabular}{|c|c|c|c|c|c|c|c|c|c|c|c|c|c|c|c|}
\hline \multirow[t]{2}{*}{$\mathrm{N}^{\circ}$} & \multirow[t]{2}{*}{$\begin{array}{c}\text { Nome } \\
\text { Paciente }\end{array}$} & \multirow[t]{2}{*}{$\begin{array}{l}\text { Idade } \\
\text { Anos }\end{array}$} & \multirow[t]{2}{*}{$\begin{array}{c}\text { Hemofilia } \\
\text { (Grau) }\end{array}$} & \multicolumn{5}{|c|}{$\begin{array}{l}\text { Hemartroses Tornozelos } \\
\text { (Pré Órteses) }\end{array}$} & \multirow[t]{2}{*}{$\begin{array}{l}\text { Consumo } \\
\text { FCD-Total } \\
\text { (UI) }\end{array}$} & \multicolumn{5}{|c|}{$\begin{array}{l}\text { Hemartroses Tornozelos } \\
\text { (Pós Órteses) }\end{array}$} & \multirow{2}{*}{$\begin{array}{c}\text { Consumo } \\
\text { FCD-Total } \\
\text { (UI) }\end{array}$} \\
\hline & & & & DIR & $\mathrm{ESQ}$ & $D+E$ & ESPONT & TRAUM & & DIR & $\mathrm{ESQ}$ & $D+E$ & ESP & TRAUM & \\
\hline 1 & ARL & 27 & A-leve & 4 & & & 4 & & 6000 & 0 & 0 & 0 & 0 & 0 & 0 \\
\hline 2 & ACA & 10 & A-grave & 4 & 2 & 3 & 9 & & 11000 & 3 & 2 & 1 & 4 & 2 & 8500 \\
\hline 3 & ADS & 21 & B-moder. & & 10 & & 7 & 3 & 16500 & 2 & 6 & & 6 & 2 & 13500 \\
\hline 4 & ASL & 16 & A-leve & 3 & & & 1 & 2 & 4000 & 0 & 0 & 0 & 0 & 0 & 0 \\
\hline 5 & BIS & 58 & A-leve & 6 & 1 & & 5 & 2 & 30500 & 0 & 0 & 0 & 0 & 0 & 0 \\
\hline 6 & BCR & 9 & A-grave & 2 & 4 & & 5 & 1 & 9000 & 5 & 3 & & 1 & 7 & 10500 \\
\hline 7 & BBA & 14 & A-grave & 2 & 11 & & 12 & 1 & 18750 & 2 & 3 & & 3 & 2 & 10750 \\
\hline 8 & BBL & 18 & A-grave & 1 & 1 & & 1 & 1 & 2000 & & 2 & & & 2 & 6000 \\
\hline 9 & BKM & 19 & A-grave & 1 & & & 1 & & 2500 & 0 & 0 & 0 & 0 & 0 & 0 \\
\hline 10 & BLGL & 18 & A-moder. & 8 & & & 6 & 2 & 6750 & 2 & 1 & & 3 & & 5250 \\
\hline 11 & CLS & 24 & A-leve & 1 & 2 & & 3 & & 3000 & 0 & 0 & 0 & 0 & 0 & 0 \\
\hline 12 & CAL & 19 & A-moder. & 2 & & & 2 & & 4000 & 3 & & & 2 & 1 & 8000 \\
\hline 13 & DES & 10 & A-moder. & 4 & 5 & & 7 & 2 & 12250 & 2 & 1 & & & 3 & 4000 \\
\hline 14 & DAMS & 15 & A-grave & 10 & 4 & & 14 & & 19500 & 1 & & & & 1 & 1500 \\
\hline 15 & DGPFF & 10 & A-grave & 1 & 5 & & 5 & 1 & 6000 & 1 & 2 & & & 3 & 12000 \\
\hline 16 & DAS & 8 & B-moder. & 3 & 6 & 1 & 7 & 3 & 13500 & 1 & 5 & & 2 & 4 & 5000 \\
\hline 17 & ELS & 14 & A-grave & 3 & & & 3 & & 4500 & 0 & 0 & 0 & 0 & 0 & 0 \\
\hline 18 & ERCS & 20 & A-leve & 1 & & & 1 & & 2000 & 0 & 0 & 0 & 0 & 0 & 0 \\
\hline 19 & $\mathrm{EF}$ & 7 & A-grave & 1 & & & 1 & & 6000 & 0 & 0 & 0 & 0 & 0 & 0 \\
\hline 20 & EMLS & 11 & A-grave & & 2 & & 2 & & 3750 & & 2 & & & 2 & 3750 \\
\hline 21 & FPR & 10 & A-moder. & & 5 & & 4 & 1 & 5250 & & 4 & & 1 & 3 & 7000 \\
\hline 22 & FAM & 10 & A-moder. & 5 & 2 & & 7 & & 9000 & 1 & 4 & & & 5 & 5000 \\
\hline 23 & FLS & 27 & A-leve & 1 & & & 1 & & 3000 & 0 & 0 & 0 & 0 & 0 & 0 \\
\hline 24 & GJM & 15 & A-moder. & 1 & & & 1 & & 1500 & 0 & 0 & 0 & 0 & 0 & 0 \\
\hline 25 & GAR & 16 & A-moder. & 5 & 3 & & 8 & & 20000 & 4 & 1 & & 1 & 4 & 13000 \\
\hline 26 & GDB & 12 & A-grave & 7 & 2 & & 9 & & 18250 & 2 & & & 1 & 1 & 3000 \\
\hline 27 & GGNS & 10 & A-grave & 1 & 2 & & 2 & 1 & 3000 & 1 & 1 & & & 2 & 4500 \\
\hline 28 & IZ & 12 & B-moder. & 3 & 1 & & 3 & 1 & 9000 & 0 & 0 & 0 & 0 & 0 & 0 \\
\hline 29 & JKLT & 11 & A-grave & 2 & 1 & & 3 & & 4750 & 2 & & & & 2 & 2750 \\
\hline 30 & JRSA & 8 & A-grave & 3 & & & 3 & & 2000 & 1 & & & & 1 & 2000 \\
\hline 31 & $\mathrm{JCN}$ & 33 & B-moder. & 2 & & & 1 & 1 & 3600 & 1 & & & & 1 & 0 (Crio) \\
\hline 32 & LFA & 9 & A-grave & 2 & 2 & & 4 & & 6500 & 0 & 0 & 0 & 0 & 0 & 0 \\
\hline 33 & LF & 21 & A-moder. & & 2 & & 2 & & 16000 & 0 & 0 & 0 & 0 & 0 & 0 \\
\hline 34 & LRN & 14 & A-moder. & 1 & 6 & 1 & 5 & 3 & 14500 & 3 & 2 & & 3 & 2 & 9500 \\
\hline 35 & MEL & 15 & A-grave & 2 & & & 1 & 1 & 4000 & 1 & & & & 1 & 750 \\
\hline 36 & MMTT & 13 & A-grave & 5 & 4 & & 5 & 4 & 43500 & 4 & 5 & & 3 & 6 & 20000 \\
\hline 37 & RRO & 5 & A-grave & & 1 & & 1 & & 250 & & 1 & & 1 & & 750 \\
\hline 38 & RLY & 25 & A-moder. & & & 1 & & 1 & 3000 & 0 & 0 & 0 & 0 & 0 & 0 \\
\hline 39 & SBMF & 14 & A-grave & 4 & & & 4 & & 18000 & 0 & 0 & 0 & 0 & 0 & 0 \\
\hline 40 & FV & 19 & A-grave & & 2 & & 2 & & 5750 & & 2 & & & 2 & 6500 \\
\hline 41 & RRM & 18 & A-grave & 2 & & & 2 & & 4500 & 2 & & & 1 & 1 & 3000 \\
\hline 42 & EFP & 18 & A-grave & 1 & 5 & & 5 & 1 & 12500 & 1 & 3 & & 1 & 3 & 8750 \\
\hline \multirow[t]{2}{*}{43} & TLA & 9 & A-moder. & 5 & 1 & & 6 & & 7500 & 8 & 3 & & 7 & 4 & 14250 \\
\hline & & 16,09 & & 109 & 92 & 6 & 175 & 32 & 390.850 & 53 & 53 & 1 & 40 & 67 & 189.500 \\
\hline
\end{tabular}


O número de hemartroses dos tornozelos e respectivos consumos de $\mathrm{FAH}$, antes e depois da intervenção, são melhor visualizados no Gráfico 6.

Gráfico 6 - Número de hemartroses e consumo de $\mathrm{FAH}$, em milhares de UI, antes (barras da esquerda) e depois (barras da direita) da avaliação podobarométrica e uso de órteses

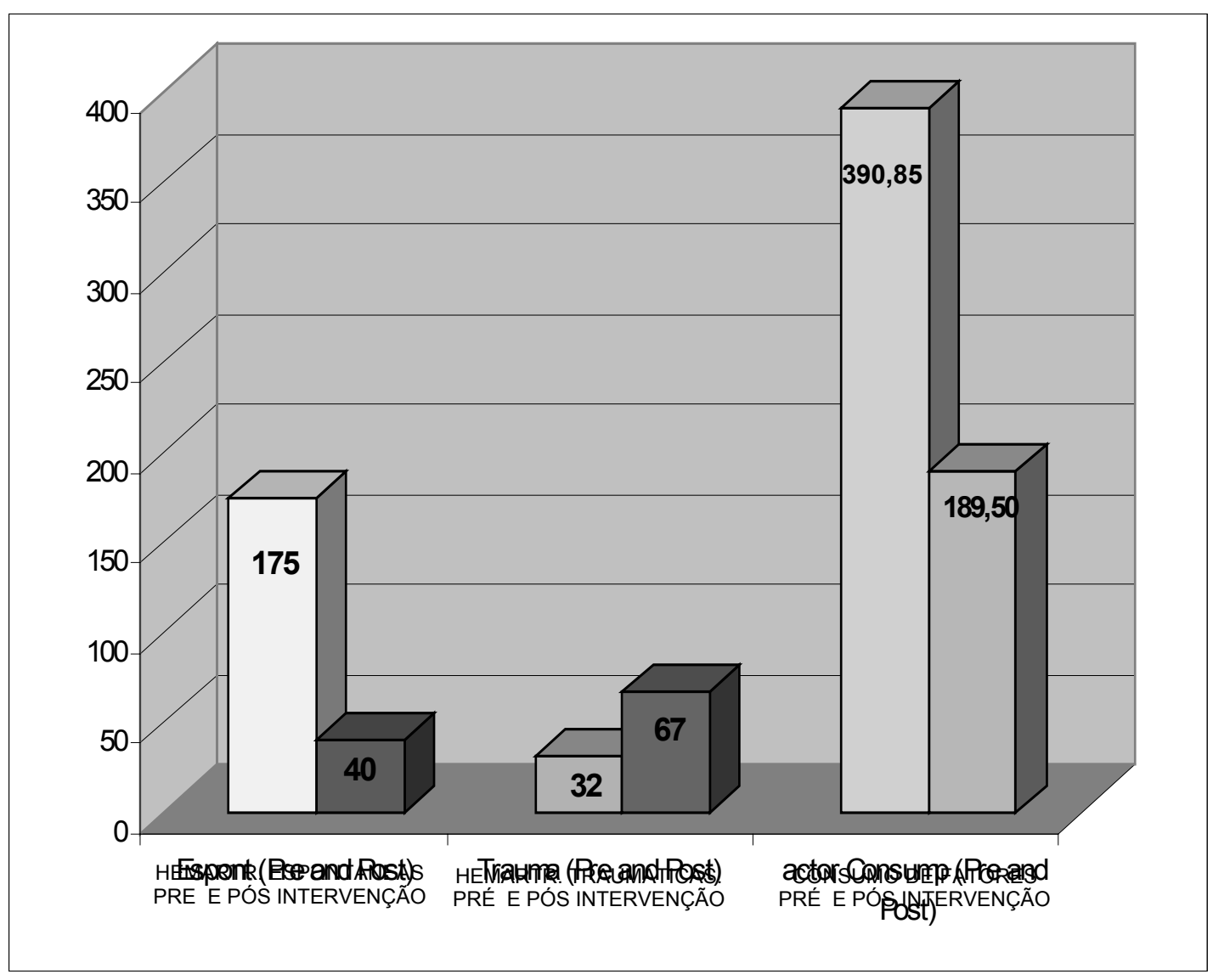

Os 43 pacientes, examinados antes e depois da intervenção, já haviam apresentado hemartroses de repetição nos tornozelos. Nem todos eles, entretanto, haviam sofrido grande número de sangramentos nos seis meses que antecederam o exame. Alguns continuaram apresentando hemartroses nos tornozelos mesmo após a aplicação das órteses.

Nos seis meses estudados após a intervenção, 3 (7\%) sofreram mais hemartroses do que antes, 6 (14\%) tiveram igual número de 
hemartroses nos dois períodos considerados e $34(79 \%)$ tiveram menos hemartroses após a intervenção. Desses últimos, 15 (44\%) não sofreram mais hemartroses nos tornozelos nos seis meses que se seguiram à intervenção.

O número total de hemartroses nos tornozelos sofridas pelos 43 pacientes que concluíram o estudo, examinados antes de serem submetidos à podobarometria, foi de 207 episódios. Após a intervenção, esse número foi reduzido para 107.

A media de ocorrência das hemartroses nos tornozelos antes da podobarometria foi 4,81. Após seis meses de estabilização das articulações pelo uso de órteses a média foi 2,53.

O consumo de fatores da coagulação, nos dois períodos de seis meses considerados na pesquisa, também apresentaram redução após a intervenção.

Nos seis meses pré-intervenção, os 43 pacientes haviam consumido $390.850 \mathrm{UI}$ de $\mathrm{FAH}$, com média=9.647,67 UI por paciente.

Nos seis meses subseqüentes ao exame podobarométrico, na avaliação feita após a adaptação às órteses, os pacientes consumiram $189.500 \mathrm{UI}$, com média de $4.407,00 \mathrm{UI}$ por paciente. A média das diferenças emparelhadas foi 5.240,7. O valor de $\boldsymbol{p}<0,001$, foi considerado estatisticamente significante.

No tornozelo direito, antes da intervenção, ocorreram 109 hemartroses com mediana=2. Nos seis meses após a intervenção ocorreram 53 hemartroses com mediana=1. A diferença entre ambas as 
medianas foi 1. A comparação feita pelo teste de Wilcoxon Signed Rank Sum mostrou $p=0,001$, estatisticamente significante.

No tornozelo esquerdo, antes da intervenção, ocorreram 92 hemartroses com mediana=1. Após a intervenção ocorreram 53 hemartroses, com mediana=0. A diferença entre as medianas foi 0 . A comparação feita pelo teste de Wilcoxon Signed Rank Sum mostrou valor de $\boldsymbol{p}=0,002$, igualmente significante do ponto de vista estatístico.

Os pacientes com lateralidade direita apresentaram maior número de hemartroses nos tornozelos esquerdos e aqueles com lateralidade esquerda no tornozelo direito.

A Tabela 5 apresenta a incidência de hemartroses conforme a lateralidade, para cada período da pesquisa, e compara os pacientes de lateralidade direita (destros) com os de lateralidade esquerda (sinistros), comprovando uma tendência dos pacientes apresentarem mais hemartroses no lado não preferencial (BUZZARD e HEIM, 1995).

Na tabela 5, a observação da coluna da diferença entre as médias reforça a constatação de que a incidência de hemartroses nos tornozelos esquerdos dos pacientes destros foi sensivelmente menor do que a incidência de hemartroses nos tornozelos direitos dos pacientes sinistros, principalmente quando se analisam ambos os períodos da pesquisa conjuntamente.

Em nosso entender caberia aqui uma pesquisa futura sobre a possibilidade desse evento ser influenciado pela dominância cerebral. Foge, porém, ao escopo deste estudo a investigação proposta. 
Tabela 5: Incidência de hemartroses nos tornozelos de 43 hemofílicos, 31 com lateralidade direita e 12 com lateralidade esquerda, comparadas pelas médias das hemorragias ocorridas em cada fase da pesquisa

\begin{tabular}{|c|c|c|c|}
\hline & $\begin{array}{l}\text { TORNOZELO } \\
\text { CONSIDERADO }\end{array}$ & $\begin{array}{l}\text { INCIDÊNCIA DE HEMARTROSES POR PACIENTE } \\
\text { LATERALIDADE (MÉDIA) : LATERALIDADE (MÉDIA) }\end{array}$ & $\begin{array}{c}\text { DIFERENÇA } \\
\text { DAS } \\
\text { MÉDIAS }\end{array}$ \\
\hline \multirow{2}{*}{$\begin{array}{l}\text { PRÉ } \\
\text { INTERVENÇÃO }\end{array}$} & PÉ DIREITO & DESTROS $(1,9)<$ SINISTROS $(3,8)$ & 1,9 \\
\hline & PÉ ESQUERDO & DESTROS $(0,5)<$ SINISTROS $(1,2)$ & 0,7 \\
\hline \multirow{2}{*}{$\begin{array}{l}\text { PÓS } \\
\text { INTERVENÇÃO }\end{array}$} & PÉ DIREITO & DESTROS $(1,3)<$ SINISTROS $(2,0)$ & 0,7 \\
\hline & PÉ ESQUERDO & DESTROS $(1,7)>$ SINISTROS $(0,8)$ & 0,9 \\
\hline \multirow{2}{*}{$\begin{array}{l}\text { PRÉ + PÓS } \\
\text { INTERVENÇÃO }\end{array}$} & PÉ DIREITO & DESTROS $(3,2)<$ SINISTROS $(5,8)$ & 2,6 \\
\hline & PÉ ESQUERDO & DESTROS $(2,2)>$ SINISTROS $(2,0)$ & 0,2 \\
\hline
\end{tabular}


Foram analisadas também as causas das hemartroses, tendo-se dividido os episódios em espontâneos e traumáticos.

Nos seis meses que antecederam a avaliação podobarométrica ocorreram, em média, 4,070 hemartroses espontâneas nos tornozelos de cada um dos 43 pacientes, totalizando 175 hemartroses. Nos seis meses após a intervenção ocorreram, em média, 0,930 hemartrose espontânea por paciente estudado, num total de 40 hemartroses. A mediana das hemartroses espontâneas no período pré intervenção foi 3 e no período pós intervenção foi 0 , com diferença igual a 3 .

A comparação feita pelo teste de Wilcoxon Signed Rank Sum mostrou ser a diferença estatisticamente significante, $p<0,001$.

Hemartroses traumáticas foram consideradas todas aquelas descritas nos prontuários como causadas por traumas como entorses, contusões e sobresforço. Na primeira etapa da pesquisa elas somaram 32 hemartroses. A mediana calculada foi 0 . Na segunda etapa ocorreram 69 sangramentos por trauma, com mediana 1. A diferença entre as medianas foi -1. Submetida ao teste de Wilcoxon Signed Rank Sum a mediana das diferenças pré e pós intervenção foi estatisticamente significante, $\boldsymbol{p}=0,004$ (DORIA FILHO, $2001 ;$ JEKEL, 2002). 


\section{DISCUSSÃO}

Diversas técnicas novas para a caracterização da distribuição da força vertical sob as superfícies plantares foram desenvolvidas nas últimas décadas.

O interesse nessas avaliações data da primeira metade do século $\mathrm{XX}$, mas só com os recentes avanços nas técnicas de computação é que se expandiram as possibilidades para a observação, coleta, mensuração, análise e apresentação sistemática dos dados referentes às pressões que agem nas superfícies plantares.

Muitos e importantes fatores contribuem para a seleção de um método de avaliação, dentre os vários que se tem hoje à disposição. Os méritos técnicos de cada sistema de avaliação devem incluir a amplitude dinâmica das forças que se deseja medir, com acurácia e repetibilidade.

Essas avaliações pressupõe um custo. Esse custo inclui não apenas o valor do equipamento em si, mas também materiais de consumo (sensores) e o tempo consumido na avaliação. Portanto, os méritos técnicos e o custo-benefício têm de ser levados em consideração ao se decidir pela aquisição de um equipamento de avaliação de movimento.

Mais importante é a capacidade de apresentar e analisar os inúmeros dados que podem ser armazenados ao se analisar dinamicamente a distribuição das forças sob a superfície plantar.

Por vezes, um único quadro ou um gráfico podem ser suficientes para apresentar as informações obtidas na avaliação, de uma maneira fácil de compreender. 
O desenvolvimento de parâmetros simples e confiáveis que demonstrem e definam, pelo comportamento da distribuição das pressões plantares, as anormalidades decorrentes das alterações patológicas ou funcionais dos pés também se reveste de importância.

De há muito se utilizam parâmetros numéricos para avaliações ortostáticas das forças que incidem nas superfícies plantares. Em geral os estudos buscam, através de avaliações feitas em plataformas de força, determinar as áreas da superfície plantar onde ocorrem as maiores concentrações de pressões (ENGSBERG et al., 1992). Esses estudos ainda têm seu lugar nas avaliações de equilíbrio (VITTAS et al., 1986; ISAKOV et al., 1992) e na localização média dos centros individuais de pressão em relação ao centro de gravidade do corpo (LORD e SMITH, 1984; SUMMERS, et al.,1987).

Houve estudos em que se utilizou, com sucesso, a plataforma de força na avaliação do desempenho, em ortostatismo, de pacientes amputados submetidos a programas de tratamento destinados à reorganização do controle postural (GEURTS et al., 1991).

Outra utilidade das avaliações das pressões que incidem nas superfícies plantares é na prevenção e cura, por meio de órteses ou de reeducação da marcha, das úlceras plantares em pacientes com pés neuropáticos (MUELLER et al., 1994).

Mais recentemente, (JORGE FILHO, 1996) optou pela podobarometria computadorizada para realizar um estudo crítico de próteses ortopédicas em que estudou dez amputados transtibiais unilaterais protetizados, tendo avaliado um tipo de pé ortopédico (Pé de 
Jaipur) de baixo custo e de confecção bastante rudimentar, comparando-o ao pé anatômico contrário ao lado amputado e ao Pé SACH. O estudo constou de duas fases, uma quantitativa e outra qualitativa. Nas avaliações quantitativas, foi feito um estudo com os pacientes em ortostatismo onde se avaliou, percentualmente, a distribuição das forças verticais na superfície plantar, e um estudo ortodinâmico, durante vários ciclos de marcha. Nesse estudo dinâmico, foram verificadas as áreas com maior incidência de picos de pressão e os tempos médios de Duração das Fases de Apoio e de Balanço. No estudo qualitativo foi estudado o deslocamento do Centro de Pressão. O autor verificou que, na maioria dos pés contralaterais à amputação, em geral o $\mathrm{CP}$ iniciava no centro do calcâneo quando do toque inicial da Fase de Apoio ("Heel strike"). A continuação se fazia no mediopé, em linha reta, pela porção central da superfície plantar ou com pequenos desvios mediais ou laterais nos pés. Já nos antepés, O CP dirigiu-se em geral para a segunda ou terceira cabeças metatársicas e daí até à polpa do Hálux, por onde os pacientes iniciavam a Fase de Balanço ("Toe off"). Nos pés SACH, cujo tornozelo é rígido, limitando a elevação do calcâneo, a TCP iniciava bem posterior no retropé e terminava nas bases dos dedos, após passar entre a segunda e a terceira cabeças metatársicas. Nos Pés de Jaipur, cujo tornozelo é bastante móvel em todos os sentidos e o calcâneo muito pronunciado, a TCP iniciava também na porção posterior do retropé, seguia reta pela porção mediana da superfície plantar no retropé e, no mediopé, sofria inflexões, ora para a borda medial ora para a borda lateral. Já no antepé, o CP ou passava entre o primeiro e o segundo dedos ou sofria desvios, 
chegando por vezes a passar entre os terceiro e quarto dedos. Ora, outros autores trabalhando com plataformas de força já haviam descrito trajetórias do $\mathrm{CP}$ bastante parecidas com aquelas constatadas por JORGE FILHO, 1996, para o pé anatômico, em pacientes que haviam sido avaliados sem calçados (GRUNDY et al., 1975; KATOH et al., 1983). A conclusão do estudo, com base nas avaliações quantitativa e qualitativa, foi que o Pé de Jaipur, por ter o tornozelo bastante móvel, condicionava marcha menos estável aos amputados, demonstrada pelos deslocamentos plantares do CP.

A revisão desse trabalho é que, mais do que a de qualquer outro, nos levou a decidir pela podobarometria e, em especial, pela análise da TCP, ao avaliarmos hemofílicos com hemartroses de repetição nos tornozelos. Afinal, a podobarometria pelo F-scan apresenta inúmeras vantagens sobre outros sistemas de avaliação dos pés.

IMAMURA, 1998, avaliou pela podobarometria dinâmica computadorizada, 100 indivíduos hígidos, com pés funcionalmente normais segundo critérios ortopédicos, calçando sapatos de sola macia e padronizados. Observou que $99 \%$ dos indivíduos submetidos às avaliações tinham uma TCP bastante idêntica, começando no centro do calcâneo e terminando na segunda (95\%) ou na primeira $(4 \%)$ cabeças metatársicas. Apenas $1 \%$ dos indivíduos tinham a TCP iniciando no calcâneo e terminando na polpa do Hálux.

Nossa casuística comportou-se ou como a de JORGE FILHO, 1996, ou como a de IMAMURA, 1998. Assim, poucos pacientes apresentaram TCF iniciando no centro do calcâneo, dirigindo-se em linha 
reta até às cabeças metatarsianas primeira, segunda ou terceira e daí até à polpa do hálux. Estes hemofílicos, particularmente, haviam desenvolvido vícios de transferência de carga à marcha tal como os amputados de JORGE FILHO, 1996. Eles procuravam transferir mais peso ao deambular, para o membro menos freqüentemente afetado por hemartroses. Essa atitude faz aumentar o tempo de permanência sobre o pé menos afetado. A maior permanência do peso do corpo sobre esses membros menos afetados, implicará num aumento da Fase de Apoio do pé menos afetado e, em decorrência, num alongamento da TCP, que atingirá então a polpa do Hálux ao final dessa fase do ciclo da marcha. Por outro lado, os pacientes que apresentavam ambos os pés saudáveis, com história de poucos antecedentes hemorrágicos, por distribuírem o peso corporal eqüitativamente nas duas extremidades inferiores, desenvolviam TCP muito semelhantes às dos indivíduos avaliados por IMAMURA, 1998, que cessavam na projeção das cabeças metatársicas primeira, segunda ou terceira.

Até então, praticamente todos os trabalhos que havíamos consultado apresentavam a TCP pela média de todos os passos em cada série gravada, analisando essas trajetórias como elementos estáticos.

Nossa proposta foi a avaliação passo a passo, com base na análise da evolução dinâmica de cada série gravada, ao visualizarmos os registros.

Baseamo-nos, para essa decisão, em um estudo de BRAND et al., 1981, que analisou a marcha de 44 pacientes, operados de pés tortos congênitos (PTC) há mais de dez anos mediante diferentes técnicas 
cirúrgicas. Sua hipótese era que, à medida que os pacientes operados de PTC apresentavam sempre pequenas deformidades ósseas residuais, esses pacientes deveriam apresentar instabilidades à marcha. Seguindo sugestão de Grundy et al.,1975, que a TCP poderia ser útil na avaliação das anormalidades dos pés, se o grau de anormalidade apresentasse correlação com a gravidade das disfunções do pé analisado, esses aa. compararam os pacientes operados de PTC com indivíduos normais. Seu raciocínio era que, se as TCP dos pacientes submetidos a cirurgias nos pés diferissem repetidas vezes daquelas produzidas por indivíduos normais, então seria possível usar a TCP como um meio de diagnóstico precoce de instabilidades nos pés de crianças submetidas a correções cirúrgicas de PTC. As avaliações foram realizadas numa plataforma de força associada a um computador, que determinou a força vertical de reação do solo à marcha, em velocidade confortável, com os indivíduos deambulando descalços. Outro dispositivo colocado sobre a plataforma de força registrou as pegadas dos indivíduos avaliados. Todas as TCP obtidas, passo a passo, em cada série registrada, foram então desenhadas sobre essas pegadas, com auxílio do computador, e seus desvios analisados segundo uma escala, que classificava a funcionalidade dos pés submetidos a cirurgias, de 0 a 100 . Seus estudos em adultos com pés normais demonstraram, através das formas das TCP resultantes do contato dos pés com o solo, que as TCP nesses indivíduos se mantiveram constantes. Por outro lado, nos indivíduos que, após terem sido operados, tinham os pés plantígrados, as áreas de contato entre o pé e o solo eram mais alargadas do que nos pés normais e as TCP muito 
variáveis. Essas duas características combinadas sugeriam que as TCP apresentavam desvios para a borda lateral dos pés. Entretanto, esses pacientes não apresentavam inversão visível dos retropés à marcha e nem calosidades nas bordas laterais dos pés.

Baseados na escala centesimal, BRAND et al., 1981, observaram que quanto pior o resultado funcional pós operatório dos pés, mais divergências ocorriam entre as TCP a cada passo avaliado. Essa constatação norteou nossa pesquisa, tanto na avaliação das instabilidades quanto na avaliação das estabilidades obtidas por meio das órteses prescritas para os pacientes.

KATOH et al., 1983 já observara que a maior ou menor flexibilidade das solas dos calçados utilizados pelos pacientes nas avaliações das pressões plantares à marcha, pouco interferia nas TCF. IMAMURA, 1998, procurou utilizar em seu estudo calçados esportes com solas de borracha macias, padronizados.

Os hemofílicos, avaliados no presente estudo, apresentavam hemartroses de repetição nos tornozelos independentemente do tipo de solado de seus calçados usuais, e portanto não era essa a variável que nos preocupava. Estabelecemos que as avaliações deveriam ser realizadas com calçados usuais, sem desgastes nos solados que pudessem alterar a distribuição das pressões nas superfícies plantares. Afinal, a TCF é função direta dos picos de pressão registrados pelos sensores durante a transferência do peso desde o calcâneo até o antepé. A tônica das nossas avaliações deveria, portanto, ser a análise das TCP, atentando para os desvios dos pés no plano frontal, passo a passo. 
Afinal, procurávamos um meio de diagnosticar instabilidades nos pés, e os estudos de BRAND et al, 1981, nos haviam apresentado uma maneira de ver as TCP exatamente como elas devem ser vistas, passo a passo, dinamicamente, como um filme.

BRAND et al, 1981, ademais, haviam radiografado os ângulos talocalcaneanos de sua casuística em anteroposterior e em perfil, e não encontraram correlações entre esses exames e os resultados obtidos pela análise das TCP. Em nossa opinião essa falta de correlação se explica pelo fato dos exames radiográficos serem ortostáticos, enquanto que a determinação das TCP constituem um exame ortodinâmico. Esse foi o motivo de termos abandonado os exames radiográficos logo no início desta pesquisa. Afinal, os resultados positivos que os primeiros pacientes estudados tinham apresentado eram decorrentes da adequada prescrição de órteses, em razão da correta interpretação das TCP, sem uma aparente correlação com as avaliações radiográficas .

Em nosso entender, todos os autores estudados, exceto BRAND et al, haviam-se fixado muito na trajetória do CP, desde o centro do calcâneo até esta ou aquela cabeça metatarsiana ou até o hálux. Outra preocupação dos autores mais antigos, que utilizavam as plataformas de força, era que os pacientes eram examinados em geral descalços. Apenas um ou outro autor avaliou indivíduos calçados com solados mais ou menos flexíveis. Porém, a essência das avaliações e do acompanhamento das correções das instabilidades não residia, em nosso entender, nesses elementos. 
Em nosso ponto de vista, os pacientes hemofílicos avaliados neste estudo sofriam hemartroses de repetição porque deambulavam continuadamente sobre pés que apresentavam disfunções, tais como desvios em valgo e varo nos retropés, que determinavam instabilidades médio-laterais. Cabia-nos encontrar um meio de comprovar esse raciocínio com resultados.

Em 1980, DRAGANICH et al.,afirmavam que à TCP era a variável mais reprodutível para repetidas avaliações dos padrões de distribuição de pressões nas superfícies plantares, de um mesmo indivíduo.

ROSE et al., 1992, investigaram as alterações provocadas pela interposição de cunhas sob os calcâneos nas pressões plantares. Seu objetivo era avaliar se o sistema F-scan de avaliação podobarométrica era suficientemente sensível para reconhecer elevações nas bordas dos retropés. Onze voluntários, seis homens e cinco mulheres com idades entre 25 e 45 anos, comprovadamente sem indícios de anormalidades nos pés, foram submetidos a testes em que realizaram um total de 12 séries de passos deambulando com interposição de cunhas, fixadas na região dos retropés, entre o solado dos sapatos e o piso. Foram definidas seis áreas da superfície plantar as quais foram monitoradas enquanto os voluntários caminhavam sobre a plataforma de força; o hálux, o segundo dedo, a região metatársica medial (área de projeção dos primeiro e segundo metatarsianos), a região metatársica lateral (área de projeção dos terceiro, quarto e quinto metatarsianos), a porção medial do retropé e a porção lateral do retropé. Interpondo cunhas com $1 / 4$ de polegada na metade lateral dos retropés, os aa. observaram significante redução das 
pressões sob as $3^{\mathrm{a}}, 4^{\mathrm{a}}$ e $5^{\mathrm{a}}$ cabeças metatársicas e igualmente significante elevação das pressões sob as $1^{a}$ e $2^{a}$ cabeças metatársicas. Interpondo cunhas com $1 / 2$ polegada sob a borda medial dos retropés, os aa. observaram ainda maiores reduções das pressões médias sob a região metatársica medial e sob o halux. Já na região metatársica lateral (dos $3^{\circ}, 4^{\circ}$ e $5^{\circ}$ metatarsianos), verificaram elevação pouco significante das pressões plantares. Esses valores de pressão eram significantemente menores quando os indivíduos foram avaliados calçando sapatos moles com solados mais flexíveis.

Porém, pelo estudo das TCP, esses aa. verificaram que a interposição de cunhas elevando as bordas laterais dos retropés em $1 / 4$ ou em $1 / 2$ polegada, deslocaram o Centro de Pressão medialmente, com maiores desvios ocorrendo no mediopé e nas regiões metatársicas. Os menores desvios ocorreram na região dos retropés. Tal como esperado, a interposição de cunhas elevando as bordas mediais dos retropés fizeram o CP desviar lateralmente. Uma vez mais, os maiores desvios da TCP ocorreram nos mediopés e nas regiões metatársicas, e os menores desvios nos retropés.

As principais conclusões desse estudo foram: a) o sistema F-scan de avaliação de marcha é um meio seguro e reprodutível de estudo das pressões que incidem nas superfícies plantares; b) a utilização de palmilhas finas e flexíveis no interior dos calçados permite avaliar os pacientes não mais descalços mas agora usando seus calçados habituais; c) os resultados desse exame permitem indicar modificações nos calçados e até procedimentos cirúrgicos, bem como monitorar-lhes os 
efeitos; d) o sistema é melhor indicado para avaliações qualitativas, como as dos desvios do CP, uma vez que seus sensores sofrem modificações pela pressão do peso corporal dos pacientes, o que interfere na acurácia dos registros de pressão. Essa experiência mostrou que os sensores se mostram confiáveis para mensuração das pressões plantares, até um máximo de seis séries de cinco passos (cerca de 30 ciclos completos de marcha). O presente estudo verificou a correlação entre os desvios dos retropés e os desvios da TCP, e procurou, baseado nas conclusões de ROSE et al, 1992, utilizar-se tantas vezes quanto possível, de cunhas elevando a metade medial ou lateral do retropé, de acordo com os desvios apresentados pelo $\mathrm{CP}$ dos pacientes antes das intervenções. Com base nos desvios das TCP encontradas na avaliação podobarométrica, eram confeccionadas palmilhas com as cunhas requeridas à estabilização dos retropés como sugerido por ROSE et al.

Os resultados do presente estudo foram concordes com a pesquisa de ROSE et al, 1992. A única diferença foi quanto às alturas das cunhas utilizadas, uma vez que trabalhávamos com pacientes de alto risco de desenvolver hemartroses nos tornozelos e portanto tínhamos de iniciar com pequenas elevações e, se necessário, aumentar a altura das cunhas com base na observação da estabilização dos retropés pelas variações da TCP. Ainda assim, concordamos quanto à segurança, ao conforto e à reprodutibilidade dos achados, mencionadas por esses aa. como vantagens do sistema F-scan. No que refere às TCP, ao introduzirmos cunhas nos retropés ou outras compensações que as avaliações mostraram ser necessárias à estabilização desses pacientes, pudemos 
com facilidade avaliar seus efeitos na estabilização dos pés de nossos pacientes.

Porém, nem todos os pacientes evoluíram satisfatoriamente usando apenas palmilhas. Alguns apresentavam na avaliação inicial desvios muito acentuados da TCP, o que significava a presença de considerável instabilidade nos retropés. Com base no histórico ambulatorial dos pacientes, todos eles vinham apresentando hemartroses nos tornozelos há mais de seis meses. Segundo HERTEL, 2002, as instabilidades crônicas dos retropés podem ser devidas a instabilidade mecânica, a instabilidade funcional ou à combinação dois dois tipos. As instabilidades mecânicas podem ocorrer devido a insuficiências específicas. As mais observadas são a frouxidão ligamentar patológica, alterações artrocinemáticas, irritação sinovial ou alterações degenerativas articulares.

Os hemofílicos submetidos a esta pesquisa, com história de hemorragias crônicas nos tornozelos seguramente apresentavam, mesmo fora das crises, pelo menos as três últimas causas. Sabe-se que as hemartroses determinam lesões degenerativas às cartilagens articulares mesmo ante curtas exposições. A ocorrência de sucessivas crises hemorrágicas fatalmente determina alterações morfológicas degenerativas nas cartilagens articulares. Essas alterações degenerativas são responsáveis pela ocorrência de disfunções artrocinemáticas, estimulando a ocorrência de novos episódios hemorrágicos, que levarão à sinovite crônica (ROOSENDAAL et al., 2000). Assim, pacientes hemofílicos com hemartroses de repetição, têm maior potencial para 
desenvolver instabilidades articulares mecânicas do que aqueles que só sangram ante estímulos traumáticos esporádicos.

Quanto às instabilidades funcionais, segundo HERTEL, 2002, consistem na ocorrência de instabilidade de repetição nos retropés associada à sensação de instabilidade articular devido deficiências proprioceptivas e neuromusculares.

Há autores que consideram as instabilidades funcionais as deficiências residuais mais comumente observadas após entorses agudos, com hemorragias, nos tornozelos (MATSUSAKA, 2001).

O mecanismo fisiopatológico causador da artropatia dos hemofílicos é bastante semelhante àquele descrito para a sinovite causada pelos entorses de repetição nos não hemofílicos, e que de acordo com alguns autores é capaz de levar à ocorrência de instabilidades articulares e à perda da cinemática articular normal. Esses autores afirmam que a associação desses fatores pode causar lesão crônica recurrente, levando precocemente à instalação de degenerações articulares (SAFRAN et al, 1999).

A cápsula articular e os ligamentos, por serem ricos em terminações nervosas, têm entre suas maiores funções prover informações proprioceptivas para a função articular. A repetição dos episódios hemorrágicos pode levar ao enrijecimento da cápsula articular e dos ligamentos, prejudicando a propriocepção. Semelhante distúrbio pode ser causado pelo uso continuado de órteses não funcionais para estabilizar os pés. Os ligamentos têm também a função de estabilizar as articulações, desse modo contribuindo para prevenir movimentos 
excessivamente amplos. Seu enrijecimento pode portanto determinar restrições aos movimentos, alterando a cinemática das articulações desses pacientes. Ademais, os ligamentos servem de guias para dirigir os movimentos articulares (SAFRAN et al, 1999), e seu enrijecimento poderá alterar os movimentos, determinando desgastes às cartilagens articulares e obrigando as estruturas capsulares a esforços adicionais para manter a congruência entre os ossos das articulações afetadas. Esse esforço adicional é que leva ao estado de sinovite crônica, que é um dos fatores determinantes de hemartroses, responsável pela perpetuação do ciclo vicioso sinovite crônica-hemartroses de repetição, que culmina com a artropatia hemofílica, onde praticamente se encontram todos os elementos citados anteriormente.

Segundo Hintermann, num estudo biomecânico dos tornozelos instáveis e suas implicações clínicas, a causa mais freqüente da instabilidade funcional crônica dos tornozelos não é a instabilidade mecânica mas a deterioração da propriocepção (HINTERMANN, 1999) .

Nos seis meses iniciais do estudo, o total de hemartroses verificado foi de 207. Nas anotações dos prontuários verificou-se que dessas 207 hemorragias nos tornozelos, $175(84,5 \%)$ constituíam hemartroses espontâneas. As hemartroses que tinham relatada uma causa traumática explícita, tais como contusões, entorses ou outras, somaram $32(15,5 \%)$ episódios.

O presente estudo demonstrou, pela análise da TCP na superfície plantar à marcha, a existência de instabilidades nos retropés dos pacientes avaliados. As palmilhas, os calçados com contrafortes ou as 
órteses funcionais, prescritas com base nos deslocamentos da TCP durante a marcha, puderam estabilizar os retropés e os tornozelos no plano frontal e contribuiram para reduzir o número de hemartroses espontâneas nos tornozelos desses pacientes.

A podobarometria realizada após uma semana e, novamente, após seis meses utilizando as órteses, mostrou redução sustentada nos desvios das linhas da TCP, sugestiva de estabilização nos pés dos hemofílicos. O controle músculo-articular assim obtido sugeriu que as instabilidades crônicas dos retropés dos hemofílicos teriam, possivelmente, as mesmas causas de instabilidades que os pés dos pacientes estudados pelos autores citados anteriormente, uma vez que com a utilização de órteses estabilizadoras reduziram consideravelmente o número de episódios de hemartroses espontâneas.

Por outro lado, as hemartroses de causa traumática aumentaram das 32, ocorridas nos seis meses iniciais, para 67 hemorragias nos tornozelos. A única explicação que encontramos para esse fato, conversando com os pacientes e seus familiares, foi que a maioria deles se sentiu mais segura para solicitar mais as articulações alvo do estudo e, fugindo às características tranqüilas da maioria dos hemofílicos, passaram a abusar de atividades envolvendo marcha e uso de bicicletas, possivelmente determinando hemartroses por sobresforço - "overuse" dos tornozelos. Nos prontuários hematológicos de alguns desses pacientes pudemos constatar anotações de ocorrências desse tipo. 
Apesar disso, nos seis meses do estudo em que os hemofílicos já estavam utilizando as órteses, houve uma economia importante nas quantidades de FAH utilizados para coibir hemartroses nos tornozelos.

A verificação das quantidades de $\mathrm{FAH}$ recebidas pelos 43 pacientes submetidos ao estudo nos seis primeiros meses da pesquisa, igualmente baseada nas anotações encontradas nos respectivos prontuários hematológicos mostrou que, naquele período, a média de consumo de FAH havia sido de 9.647,67 UI por paciente.

A persistir esse consumo, ao fim de um ano cada um desses pacientes teria consumindo, em média, 19.295,34 UI, muito próximo da estimativa de consumo anual, per capita, estabelecida pelo Ministério da Saúde em 1994, para compra e fornecimento dos $\mathrm{FAH}$ aos pacientes registrados nos hemocentros do país, então estimada em 20.000 UI.

Em nossa casuística, antes da intervenção com órteses, o consumo médio por paciente havia sido de 1.515 UI mensais, pois esses hemofílicos estavam sendo submetidos a programas de reabilitação (BATTISTELLA, 1998a) que incluíam cuidados fisioterápicos (BUZZARD, 1997; BEETON et al, 1998) medidas de condicionamento físico para fortalecimento muscular e uso de órteses para repouso articular na fase aguda das hemartroses (HEIJNEN et al, 1997; BATTISTELLA, 1998b; EILS et al, 2002), além de se beneficiarem das Doses Domiciliares de Urgência (DDU), uma vez que todos residem em regiões onde esse programa já se encontrava em vigor.

Os dados até então observados nos prontuários e a literatura consultada conduziram este estudo. 
Através da avaliação das TCP e da prescrição de órteses delas decorrente, se não foi possível eliminar de vez as hemartroses nos tornozelos, conseguiu-se ao menos reduzir o número daquelas de ocorrência espontânea.

Na segunda etapa da pesquisa, os prontuários hematológicos dos 43 hemofílicos que completaram o estudo foram novamente consultados.

Verificou-se uma redução no número de episódios de hemartrose sofridos, após seis meses em uso das órteses. O número total de hemartroses nos tornozelos que fora de 207 episódios, foi reduzido para 107. Com essa redução no número de hemartroses nos tornozelos, ocorreu redução proporcional no consumo dos FAH que baixou, na totalidade dos pacientes, das $390.850 \mathrm{UI}$ consumidas na primeira fase do estudo, para $189.500 \mathrm{UI}$, o que representa uma economia de $51,5 \%$ no total de FAH consumidos pelos pacientes depois que passaram a utilizar as órteses baseadas na TCP.

Como se esperava, o número de episódios hemorrágicos espontâneos nos tornozelos diminuiu de modo significante, dos 175 episódios observados anteriormente, para apenas 40, após a utilização das órteses.

As avaliações podobarométricas realizadas na primeira fase da pesquisa mostravam trajetórias irregulares, com linhas divergentes, por vezes fugindo aos limites das superfícies plantares, sugestivas de instabilidades articulares nos tornozelos ou nos retropés. Já nesta segunda etapa, com os pacientes utilizando as órteses, verificou-se uma 
tendência da TCP de percorrer a porção mais central da superfície plantar, na totalidade da Fase de Apoio da marcha.

Essa tendência está de acordo com as observações de autores que estudaram a TCP em exames podobarométricos dinâmicos computadorizados de pessoas normais, no controle da utilização de órteses (ROSE et al, 1992; SCHERER \& SOBIESK, 1994; HAN et al, 1999), e em pacientes com diferentes distúrbios afetando as superfícies plantares dos pés, como nos pés reumatóides (LI et al, 2000; ORLIN \& Mc POIL, 2000).

Embora a análise da Trajetória do Centro de Força seja qualitativa (ROSE et al, 1992) o sistema utilizado forneceu, à medida que eram adicionados elementos destinados a estabilizar funcionalmente os tornozelos e os retropés, resultados reprodutíveis e de fácil identificação (Fig.13 ), associados a resultados clínicos substanciais (Gráfico 6).

A prescrição de palmilhas com cunhas e almofadas, elaborada com base nos achados dos desvios da TCP, mostrou ser eficiente no controle das instabilidades funcionais previamente observadas ao exame podobarométrico.

Nos países desenvolvidos uma das maneiras de se evitar a ocorrência de episódios hemorrágicos, é submeter os hemofílicos a infusões parenterais contínuas de doses dos $\mathrm{FAH}$, ministradas desde os primeiros anos de vida (tratamento profilático; TP). Há instituições, como o Hospital Universitário de Malmö, Suécia, em que as crianças são submetidas ao TP a partir de um ano e meio de vida consumindo, em média, 4.000 a 9.000 UI do FAH por quilo de peso corporal por ano, na 
faixa etária de 3 a 12 anos. Os hemofílicos $A$ são submetidos a 3 infusões semanais e os hemofílicos B a duas. Conforme os pacientes vão crescendo, as quantidades de $\mathrm{FAH} / \mathrm{Kg} /$ ano necessárias à profilaxia das hemorragias diminuem. Na faixa etária de 13 a 20 anos, as quantidades consumidas variaram entre 1.600 e $5.400 \mathrm{Ul} / \mathrm{Kg} / \mathrm{ano}$, enquanto na faixa etária de 21 a 35 anos foram consumidas entre 400 e 3.300 Ul/Kg/ano. Os três grupos mostraram redução no número de episódios hemorrágicos (LJUNG,1998).

Essa profilaxia, segundo seus defensores, evita a deterioração das cartilagens articulares, conhecida como Artropatia Hemofílica (RIBBANS \& PHILLIPS, 1996), melhora a qualidade de vida dos hemofílicos (MOLHO et al, 2000), reduz o número de episódios hemorrágicos e, por isso, reduz as necessidades assistenciais dos pacientes (SZUCS et al, 1998).

Liesner e seus colaboradores avaliaram os resultados do fornecimento regular do FAH a 27 hemofílicos com média de 6,2 anos de idade durante 30 meses. Nesse período consumiram, em média, 4.900 $\mathrm{UI} / \mathrm{Kg} / \mathrm{ano}$ de $\mathrm{FAH}$ e, ao final da pesquisa, todos os 20 pacientes que tinham evidências de Artropatia Hemofílica apresentaram melhora. Desses, oito apresentaram regressão completa das lesões articulares. Esses autores concluíram que os pacientes tiveram melhoras na qualidade de vida, visto terem diminuído o número das admissões hospitalares e o número de dias de aulas perdidos por episódios hemorrágicos, além de não terem mais a necessidade de utilizar muletas (LIESNER et al. 1996). 
Porém, há estudos mostrando que o custo dos FAH corresponde a algo em torno de $93 \%$ do custo total do tratamento dos hemofílicos, razão pela qual, apesar de todas as vantagens que apresenta, o tratamento profilático amplia substancialmente o custo do tratamento médico da hemofilia (SCHRAMM \& BERGER, 2002).

O presente estudo mostrou ser possível obter uma redução no número de hemartroses dos tornozelos e, em decorrência, no consumo dos FAH apenas com a adaptação de órteses para os pés.

O período de um ano de observação aplicado neste estudo, dividido em duas fases com seis meses de observação em cada etapa, foi suficiente para se chegar às conclusões e está de acordo com outros trabalhos publicados.

Szucs e seus colaboradores, num estudo multicêntrico realizado em 16 hemocentros de 10 países europeus, no qual foram acompanhados 566 hemofílicos, dividiram a casuística em dois grupos: aqueles tratados com reposição dos $\mathrm{FAH}$ apenas nas crises e aqueles submetidos ao TP. Os primeiros consumiram em média 38,3 $\mathrm{UI} / \mathrm{Kg} / \mathrm{semana}$, enquanto aqueles submetidos ao TP consumiram 68,6 $\mathrm{UI} / \mathrm{Kg} / \mathrm{semana}$. Confirmando as expectativas do autor, o grupo submetido ao TP apresentou apenas 3,1 hemartroses por paciente, nos seis meses avaliados, enquanto o grupo que recebia os FAH apenas nas crises, apresentou em média 8,8 hemartroses (SZUCS et al., 1998).

Em nossa casuística, levando-se em consideração apenas os tornozelos, observamos uma redução na média de hemartroses. Essa variação foi dos 4,81 episódios sofridos, em média, por paciente nos seis 
primeiros meses da pesquisa, para 2,53 hemartroses por paciente, nos seis meses em uso de órteses. Creditamos essas médias, abaixo daquelas divulgadas naquele estudo europeu, aos esforços conjuntos dos serviços de hemoterapia e de reabilitação de nosso país em prover esses pacientes de cuidados de reabilitação preventiva com fortalecimento muscular, melhora da capacidade física aos esforços e, quando necessário, a prescrição de períodos de repouso ou a utilização das órteses não funcionais. O repouso articular após a ocorrência de sangramentos articulares é importante na cura. Porém o uso de palmilhas, calçados com contrafortes e órteses semi-rígidas, restringindo os movimentos de inversão e de eversão dos retropés dos pacientes, reduz as instabilidades articulares nos retropés e libera consideravelmente os movimentos de dorsi e de plantiflexão, permitindo mobilidade controlada nos tornozelos para o desempenho das atividades da vida diária e profissionais. Essa redução nas amplitudes dos movimentos, contribui para evitar ou reduzir a intensidade dos acidentes hemorrágicos articulares.

Dos 43 pacientes avaliados, 15 não sofreram nenhuma hemartrose nos tornozelos após começarem a usar as órteses. A média de consumo dos $\mathrm{FAH}$, nos seis meses, baixou de $9.647,67$ para $4.407,00$, por paciente.

Os resultados obtidos neste trabalho sugerem que as hemartroses, em todas as articulações em que venham a ocorrer, podem ter sua freqüência reduzida ao mesmo tempo em que os pacientes podem manter-se ativos, se as articulações são adequadamente estabilizadas. 
Esperamos que os resultados obtidos nesta pesquisa estimulem novos estudos biomecânicos, especialmente dirigidos ao estabelecimento de uma relação de causa-efeito entre hemartroses dos tornozelos e instabilidades articulares que enfatizem as deficiências proprioceptivas, visto que os recursos que estiveram ao nosso dispor, embora tendo-nos levado a crer que as instabilidades dos tornozelos são as maiores responsáveis pelas hemartroses de repetição naquelas articulações, não nos permitiram determinar quantitativamente as causas dessas instabilidades.

Acreditamos, baseado na literatura pesquisada e nas observações que permearam este estudo, que as deficiências proprioceptivas determinadas pelas lesões dos tecidos articulares quando das hemartroses de repetição, possam ser uma das causas das instabilidades que a podobarometria dinâmica computadorizada encontrou nos tornozelos dos pacientes observados. Somos de opinião que um trabalho com exercícios proprioceptivos controlados e de intensidade crescente, deva levar a bons resultados naqueles pacientes que não responderam bem ao uso de órteses funcionais no controle das hemartroses dos tornozelos, contribuindo também para a redução do consumo dos $\mathrm{FAH}$. 


\section{CONCLUSÕES}

As principais conclusões deste estudo foram:

1. as instabilidades articulares comprovadamente contribuem para a ocorrência de hemartroses nos tornozelos dos hemofílicos;

2. a podobarometria dinâmica computadorizada é um meio estatisticamente significante de diagnóstico das instabilidades dos tornozelos e dos retropés;

3. pela interpretação correta dos resultados da podobarometria podem-se prescrever órteses simples e confortáveis, reduzindo-se a ocorrência de hemartroses nos tornozelos dos hemofílicos e, em decorrência, reduzindo-se o consumo dos FAH;

4. a utilização das órteses foi fator determinante para o controle das hemartroses de repetição neste estudo. 


\title{
ANEXO A : \\ Aprovação da Comissão de Ética em Pesquisa
}

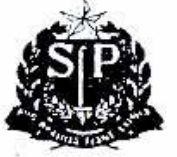

\author{
HOSPITAL DAS CLINICAS \\ DA FACUIDADE DE MEDICINA DA UNIVERSIDADE DE SÄO PAUUO \\ CAIXA POSIAL, 3471 - SÄO PAULLO-BRASHL. \\ DIRETORIA CLIINICA
}

Comissão de Ética para Análise de Projetos de Pesquisa

\section{APROVAÇÃO}

A Comissão de Ética para Análise de Projetos de Pesquisa - CAPPesq da Diretoria Clínica do Hospital das Clínicas e da Faculdade de Medicina da Universidade de São Paulo, em sessão de 26.06.03, APROVOU o Protccolo de Pesquisa $n^{\circ}$ 241/03, intitulado: "Hemartroses recidivantes dos tornozelos em hemofílicos: Diagnóstico funcional baseado nos resultados da podobarometria dinâmica computadorizada" apresentado pelo Departamento de CLÍNICA MÉDICA, bem como o Termo de Consentimento Livre e Esclarecido.

Pesquisador(a) Responsável: PROFA. DRA. LINAMARA RIZZO BATTISTELLA

Pesquisador(a) Executante: DR. DONALDO JORGE FILHO

CAPPesq, 26 de Junho de 2003.

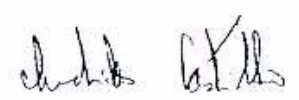

PROF. DR. EUCLIDES AYRES DE CASTILHO

Presidente da Comissão de Ética para Análise de Projetos de Pesquisa

OBSERVAÇÃO: Cabe ao pesquisador elaborar e apresentar à CAPPesq, os relatórios parciais e final sobre a pesquisa (Resolução do Conselho Nacional de Sauide $n^{\circ} 196$, de 10.10.1996, inciso IX.2, letra " $c$ ") 


\section{ANEXO B - Planilha para Coleta dos Dados Ambulatoriais}

Nome:

Tipo de Hemofilia:

Nome da mãe:

Cidade:
Lateralidade :( )Pé Dir - ( )Pé Esq Endereço:

CEP:
Nascimento:

Institução de Origem:

CPF:

Fone:

\begin{tabular}{|c|c|c|c|c|c|c|c|}
\hline \multicolumn{3}{|c|}{$\begin{array}{l}\text { HEMARTROSES DE TORNOZELO } \\
\text { DE: -- - A:-- } \\
\text { (6 meses antes da podobarometria, sem órteses) }\end{array}$} & \multirow[t]{2}{*}{$\begin{array}{l}\text { TOTAL FAH } \\
\text { RECEBIDO }\end{array}$} & \multicolumn{3}{|c|}{$\begin{array}{l}\text { HEMARTROSES DE TORNOZELO } \\
\text { DE: }--- \\
\text { (6 meses após a podobarometria, com órteses) }\end{array}$} & \multirow[t]{2}{*}{$\begin{array}{l}\text { TOTAL FAH } \\
\text { RECEBIDO }\end{array}$} \\
\hline DIREITO & ESQUERDO & AMBOS & & DIREITO & ESQUERDC & AMBOS & \\
\hline & & & & & & & \\
\hline & & & & & & & \\
\hline & & & & & & & \\
\hline & & & & & & & \\
\hline & & & & & & & \\
\hline & & & & & & & \\
\hline & & & & & & & \\
\hline & & & & & & & \\
\hline & & & & & & & \\
\hline & & & & & & & \\
\hline & & & & & & & \\
\hline & & & & & & & \\
\hline & & & & & & & \\
\hline & & & & & & & \\
\hline & & & & & & & \\
\hline & & & & & & & \\
\hline
\end{tabular}




\title{
ANEXO C
}

\author{
HOSPITAL DAS CLÍNICAS \\ DA
}

FACULDADE DE MEDICINA DA UNIVERSIDADE DE SÃO PAULO

TERMO DE CONSENTIMENTO LIVRE E ESCLARECIDO

(Instruções para preenchimento no verso)

\section{I - DADOS DE IDENTIFICAÇÃO DO SUJEITO DA PESQUISA OU RESPONSÁVEL LEGAL}

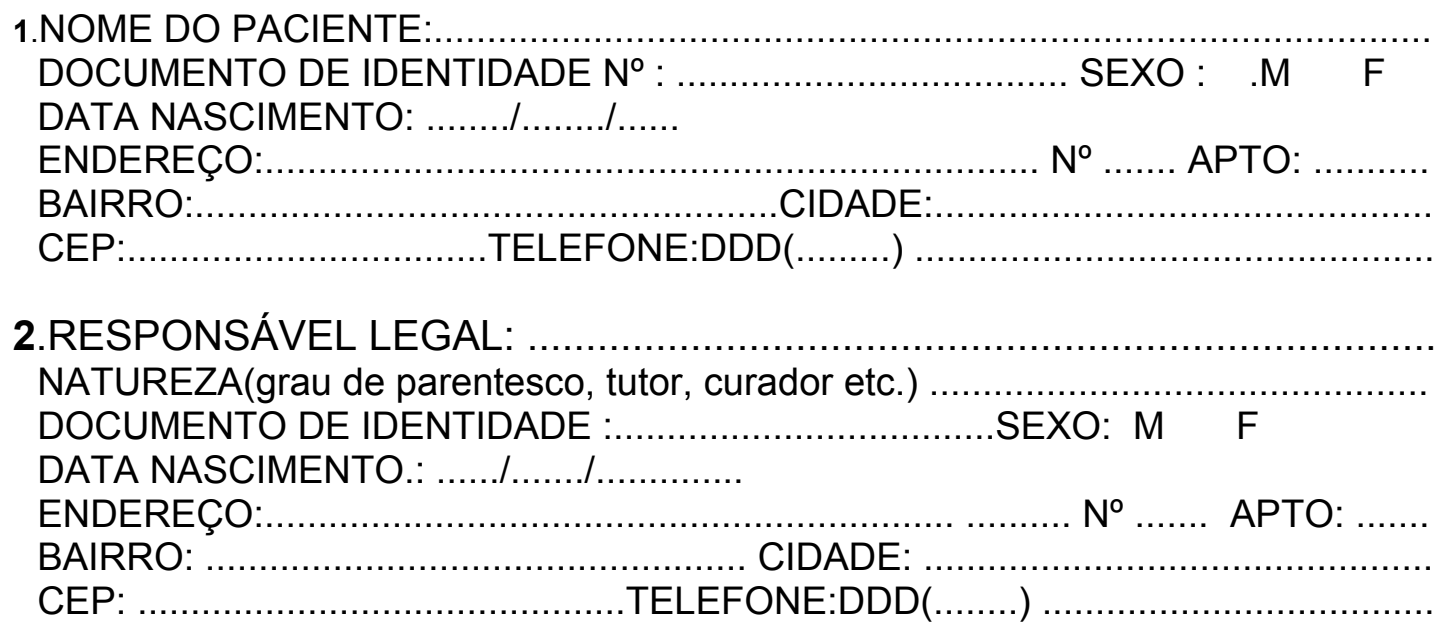

\section{II - DADOS SOBRE A PESQUISA CIENTÍFICA}

1. TítULO DO PROTOCOLO DE PESQUISA: Hemartroses recidivantes dos tornozelos em hemofílicos diagnóstico funcional baseado nos resultados da podobarometria dinâmica computadorizada e profilaxia mediante o uso de órteses para os pés.

PESQUISADOR:

DONALDO JORGE FILHO (Mestre em Reabilitação pela UNIFESP-Escola Paulista de Medicina)

CARGO/FUNÇÃO:

MÉDICO FISIATRA ASSISTENTE DA DMR-HC-FMUSP

INSCRIÇÃO CONSELHO REGIONAL : 24193 - CREMESP

UNIDADE DO HCFMUSP: FUNCIONÁRIO DA DIVISÃO DE MEDICINA DE REABILITAÇÃO - DMR-ICHC, CURSANDO O PÓS-GRADUAÇÃO EM GRAU DE DOUTOR NA DISCIPLINA DE REUMATOLOGIA DA FMUSP. 
3. AVALIAÇÃO DO RISCO DA PESQUISA:

$\begin{array}{lll}\text { SEM RISCO } & \text { RISCO MÍNIMO X } & \text { RISCO MÉDIO } \\ \text { RISCO BAIXO } & \text { RISCO MAIOR } & \end{array}$

(probabilidade de que o indivíduo sofra algum dano como consequência imediata ou tardia do estudo)

4.DURAÇÃO DA PESQUISA:

TRÊS ANOS (06-06-2001 a 06-06-2004)

\section{III - REGISTRO DAS EXPLICAÇÕES DO PESQUISADOR AO PACIENTE OU SEU REPRESENTANTE LEGAL SOBRE A PESQUISA, CONSIGNANDO:}

1. Justificativas e os objetivos da pesquisa:

Procurar saber porque ocorrem sangramentos nas juntas dos tornozelos sem que os pacientes com hemofilia façam movimentos bruscos, tais como traumatismos ao saltar de lugares altos, descer escadas apressadamente, correr, chutar objetos pesados, etc. O principal objetivo do estudo é evitar a ocorrência desses sangramentos através da utilização de palmilhas ou tornozeleiras feitas de material emborrachado, que deverão ser colocadas no interior dos sapatos para firmar os tornozelos. Essas palmilhas, nos pacientes que têm pés tortos, darão apoio aos pés evitando que ao andar eles entortem ainda mais com o peso do corpo, o que poderia levar a inflamações das juntas dos tornozelos (sinovites). A ocorrência dessas inflamações acaba causando as hemorragias das juntas. A repetição dessas hemorragias pode causar sérios desgastes aos ossos, ligamentos e músculos, o que acaba causando deformidades e rigidez das juntas a médio e longo prazo, com riscos de incapacidade para andar.

2. Procedimentos que serão utilizados e propósitos, incluindo a identificação dos procedimentos que são experimentais:

a) Deverão ser efetuadas observações das plantas dos pés, com os pacientes em pé sobre uma mesa de ferro com tampo de vidro inquebrável, que tem na parte de baixo um espelho onde o médico possa enxergar possíveis defeitos na maneira do paciente pisar, quando parado.

b) Serão realizados exames nos pacientes que deverão caminhar com calçados de uso habitual. Dentro dos calçados serão colocados sensores de pressão em forma de palmilhas, feitos de material flexível semelhante a papel celofane, com menos de $1 \mathrm{~mm}$ de espessura. Esses sensores deverão estar ligados a duas caixinhas de plástico que guardarão as informações recebidas 
pelas palmilhas enviando os dados para um computador aonde serão analisados. O computador fará a análise das pressões, e registrará a trajetória do centro de força do paciente, à medida em que o peso corporal vai sendo transferido desde os calcanhares até a frente dos pés, conforme o paciente vai caminhando no interior da sala.

c) Para esse estudo resolvemos registrar 06 a 10 passos normais de cada paciente, andando para frente no plano. Para que não se registrem dados alterados por dores nos tornozelos, joelhos, etc., os pacientes só deverão ser avaliados após o término das dores e do inchaço causado pelos sangramentos das juntas.

\section{3) Desconfortos e riscos esperados:}

Apenas o incomodo de se dirigir, com hora marcada, à Divisão de Medicina de Reabilitação - DMR do HC-FMUSP, para realizar dois exames em um mês (um exame inicial, ao fim do qual serão prescritas as palmilhas e/ou tornozeleiras necessárias para estabilizar os tornozelos afetados, outro, após pelo menos quinze dias de utilização das palmilhas e/ou tornozeleiras prescritas para o paciente) e pelo menos uma avaliação seis meses depois do início da utilização das palmilhas e/ou tornozeleiras.

4) Benefícios que poderão ser obtidos:

a) Para os pacientes: término de sangramentos espontâneos nos tornozelos dos hemofílicos. Em alguns casos, nos quais os pacientes estiverem utilizando tornozeleiras estabilizadoras, é possível que mesmo em caso de pequenos incidentes potencialmente causadores de sangramento, esses não venham a ocorrer, evitando-se a ocorrência de hemorragias ou, caso estas ocorram, diminuindo-se as quantidades de sangue no interior das articulações.

b) Para o Sistema Único de Saúde (SUS) diminuir a preocupação com os frequentes episódios de sangramento espontâneos nos tornozelos dos hemofílicos, responsáveis por $38,24 \%$ de todos os sangramentos nas crianças hemofílicas entre 0 e 10 anos de vida e por $26,14 \%$ de todos os sangramentos nos hemofílicos entre os 10 e os 20 anos de vida (Akopian, STG; Sposito, MMM \& Masiero, D. F Méd (Br), 1992 104 (4); 141: 145), o que permite uma economia considerável em recursos para a compra de fatores VIII e IX da coagulação.

\section{5) Procedimentos alternativos que possam vir a ser vantajosos para o paciente:}

a) Tratamento para a reeducação de postura, sempre que os hemofílicos apresentarem alteração de postura em outras juntas dos membros inferiores, coluna e membros superiores, 
potencialmente responsáveis por situação de sobrecarga e, por causa disso, episódios de hemorragia nas juntas.

b) Com base nos resultados desses exames, os pacientes que apresentarem desvios de postura dos pés e tornozelos (pés tortos), receberão palmilhas, tornozeleiras ou ambos, para redistribuir as pressões na planta dos pés e realinhar os tornozelos. Esta palmilhas e/ou tornozeleiras darão suporte, entre outras estruturas, aos arcos das plantas dos pés auxiliando na estabilização das juntas dos tornozelos.

c) Desse modo será evitado que pequenos traumatismos causados por desvios das juntas, que se repetem a cada passo, possam causar inflamações das juntas e por isso causar sangramentos nos tornozelos dos pacientes. As palmilhas e as tornozeleiras deverão ser fabricadas de maneira a apoiar os pés e corrigir as deformidades encontradas no exame realizado com o auxílio do computador.

\section{IV - ESCLARECIMENTOS DADOS PELO PESQUISADOR SOBRE GARANTIAS DO SUJEITO DA PESQUISA:}

a) Acesso, a qualquer tempo, às informações sobre procedimentos, riscos e benefícios relacionados à pesquisa, inclusive para dirimir eventuais dúvidas: Os resultados de todos os testes deverão ser registrados no prontuário médico dos pacientes na DMR-HC-FMUSP, ficando à disposição dos pacientes e, naqueles menores de 18 anos, de seus pais ou responsáveis legais, podendo ser solicitadas cópias desses registros a qualquer momento, para fins médico-legais ou para instruir processos diagnósticos e terapêuticos que concorram para melhorar a saúde e a qualidade de vida dos pacientes.

b) Liberdade de retirar seu consentimento a qualquer momento e de deixar de participar do estudo, sem que isto traga prejuízo à continuidade da assistência: $O$ presente estudo objetiva colher dados que permitam tirar conclusões sobre a utilidade dos procedimentos diagnósticos e das prescrições de órteses dele docorrentes, valendo-se para tanto de pacientes encaminhados à DMR-HC-FMUSP e registrados como pacientes do Programa de Reabilitação aos Hemofílicos, sendo a participação no estudo um ato voluntário de cada paciente e respectivos responsáveis, passível de cancelamento por vontade unilateral daqueles a qualquer momento, sem prejuízo dos demais atendimentos que estejam recebendo na instituição. 
c) Salvaguarda da confidencialidade, sigilo e privacidade: $O$ presente estudo, sendo um procedimento médico, respeitará as normas estabelecidas pelo Código de Ética Médica e as disposições da Comissão de Ética Médica da Faculdade de Medicina da Universidade de São Paulo. Será solicitado a todos os pacientes voluntariamente participantes do estudo que, após tomarem conhecimento de que as imagens tomadas durante seus exames na instituição poderão ser veiculadas em posteriores trabalhos científicos, aulas, apresentações gráficas e na mídia eletrônica (TELEMEDICINA-INTERNET), assinem um documento autorizando essa divulgação. A não concordância do paciente ou de seus responsáveis com a veiculação de sua imagem, com ou sem ocultação do rosto e identificada apenas pelas iniciais do seu nome, não implicará nenhum prejuízo à sua condição de paciente da instituição e de participante do estudo até sua conclusão.

d) Disponibilidade de assistência no HCFMUSP, por eventuais danos à saúde, decorrentes da pesquisa: Apesar dos procedimentos adotados tanto nas avaliações quanto na prescrição das órteses supramencionadas não serem de ordem a causar quaisquer malefícios à integridade dos pacientes submetidos ao estudo, a DMR assegura a continuidade dos tratamentos necessários a sanar eventuais agravos à saúde, decorrentes desses procedimentos, em quaisquer serviços existentes no complexo hospitalar do HC-FMUSP.

e) viabilidade de indenização por eventuais danos à saúde decorrentes da pesquisa: Sendo o HC um hospital universitário credenciado pelo Sistema Único de Saúde-SUS para provimento da saúde à população nos níveis primário, secundário e terciário, eventuais agravos à integridade física ou à saúde dos pacientes, ocorridos nos locais em que serão submetidos às avaliações necessárias à conclusão do presente estudo, deverão ser ressarcidos de conformidade com as leis que regem a Previdência Social em nosso país.

V. INFORMAÇÕES DE NOMES, ENDEREÇOS E TELEFONES DOS RESPONSÁVEIS PELO ACOMPANHAMENTO DA PESQUISA, PARA CONTATO EM CASO DE INTERCORRÊNCIAS CLÍNICAS E REAÇÕES ADVERSAS:

\section{PESQUISADOR PRINCIPAL :}

- Dr. Donaldo Jorge Filho -DMR:R.Diderot,43 - V.Mariana, São Paulo, SP - Fone:(0xx11) 5549-0111 ; RES: R. Nicarágua, 129 Jd. Das Nações, Taubaté, SP - CEP 12030-500, Fone: (0xx12) 2326600 ; 232-5438. E-mail: donaldo jorge@ig.com.br 


\section{ORIENTADOR DA PESQUISA :}

- Profa. Dra. Linamara Rizzo Battistella - DMR: R. Diderot, 43 V.Mariana, São Paulo, SP - Fone: (0xx11) 5549-0111; 5549-7501 E-mail: linamara@usp.br.

VI. OBSERVAÇÕES COMPLEMENTARES:

\section{VII - CONSENTIMENTO PÓS-ESCLARECIDO}

Declaro que, após convenientemente esclarecido pelo pesquisador e ter entendido o que me foi explicado, consinto em participar do presente Protocolo de Pesquisa

São Paulo, de de 200

assinatura do sujeito da pesquisa ou responsável legal

assinatura do pesquisador (carimbo ou nome Legível) 


\section{REFERÊNCIAS BIBLIOGRÁFICAS}

Akopian STG, Sposito MMM, Masiero D. Artropatia hemofílica: estudo epidemiológico de pacientes atendidos pela Disciplina de Fisiatria da Escola Paulista de Medicina. F Méd (Br) 1992; 104(4):141-5.

Aledort LM, Haschmeyer RH, Pettersson H \& The Orthopaedic Outcome Study Group. A Longitudinal study of orthopaedic outcomes for severe factor-VIII-deficient haemophiliacs. J Intern Med. 1994; 236(4): 391-9.

Aznar JA, Magallón M, Querol F, Gorina E, Tusell JM. The orthopaedic status of severe haemophiliacs in Spain. Haemophilia, 2000; 6:170-6.

Batorova A, Martinowitz U. Continuous infusion of coagulation factors. Haemophilia, 2002; 8:170-7.

Battistella LR. Maintenance of musculoskeletal function in people with haemophilia. Haemophilia, 1998a; 4(supl 2): 26-32.

Battistella LR. Rehabilitation in haemophilia-options in the developing world. Haemophilia, 1998b; 4(supl 2): 486-490.

Beeton K, Cornwell J, Alltree J. Muscle rehabilitation in haemophilia. Haemophilia. 1998; 4(4): 532-7.

Brand RA, Laaveg SJ, Crowninshield RD, Ponseti IV. The center of pressure path in treated clubfeet. Clin Orthop, 1981;160:43-7

Buzzard BM. Physiotherapy for prevention and treatment of chronic hemophilic synovitis. Clin Orthop, 1997;(343): 42-6. 
Buzzard BM, Heim M. A study to evaluate the effectiveness of "Air-Stirrup" splints as a means of reducing the frequency of ankle haemarthroses in children with haemophilia A and B. Haemophilia, 1995; 1: 131-6.

Buzzard BM. Proprioceptive training in haemophilia. Haemophilia, 1998; 4(4): 528-31.

Cordova ML, Ingerssol CD, Palmieri RM. Efficacy of prophylactic ankle support: an experimental perspective. J Athl Train, 2002; 37(4): 446-57.

Denegar CR, Miller SJ. Can chronic ankle instability be prevented? Rethinking management of lateral ankle sprains. J Athl Train, 2002; 37(4): 430-35.

Diez-Ewald M, Urdaneta, A. Hemofilia Revision. Invest Clin. 1983; 24 (1): 17-56.

Doria Filho U. Introdução à Bioestatística. $5^{\text {a }}$ ed. São Paulo, Negócio Editora; 2001.

Draganich LF, Andriacchi TP, Strongwater AM, Galante JO. Electronic measurement of instantaneous foot-floor contact patterns during gait. $J$ Biomech, 1980; 13:875-80.

Eils E, Demming C, Kollmeier G, Thorwesten L, Völker K, Rosenbaum D. Comprehensive testing of 10 different ankle braces - Evaluation of passive and rapidly induced stability in subjects with chronic ankle instability. Clin Biomech. 2002; 17: 526-35.

Engsberg JR, Tedford KG, Springer MJN, Harder JA. Weight distribution of bellow-knee amputee and able-bodied children during standing. Prosthet Orthot Int, 1992; 16:200-02. 
Feldman BM. Preventing joint damage from haemophilia. J Rheumatol. 2000; 7: 1579-81.

Geurts ACH, Mulder TW, Nienhuis B, Rijken RAJ. Dual-task assessment of reorganization of postural control in persons with lower limb amputation. Arch Phys Med Rehabil, 1991; 72:1059-64.

Grundy M, Tosh PA, McLeish RD, Smidt L. An investigation of the centers of pressure under the foot while walking. J Bone Joint Surg Br, 1975; 1:98103.

Han TR, Paik NJ, Im MS. Quantification of the path of center of pressure (COP) using an F-scan in-shoe transducer. Gait Posture. 1999; 10: 24854.

Heijnen L, Roosendaal G, Heim M. Orthotics and rehabilitation for chronic hemophilic synovitis of the ankle. Clin Orthop Rel Res, 1997; 343: 68-73

Heim $M$, Horoszowski $H$, Martinowitz $U$. Leg-length inequality in hemophilia. Clin Pediat, 1985; 24(10): 600-2.

Heim M, Martinowitz U, Horoszowski H. Orthotic Management of the knee in patients with hemophilia. Clin Orthop Rel Res, 1997; (343):54-7.

Hertel J. Functional anatomy, pathomechanics and pathophysiology of lateral ankle instability. J Ath/Train. 2002; 37(4):364-375.

Hintermann B. Biomechanics of the unstable ankle joint and clinical implications. Med Sci Sports Exerc. 1999; 31 (7): S459-S69.

Hughes J. The clinical use of pedobarography. Acta Orthop Belg, 1993; 59(1):10-6. 
Imamura Marta. Avaliação podobarométrica do pé do homem adulto normal [tese]. São Paulo: Faculdade de Medicina, Universidade de São Paulo; 1998.

Isakov E, Mizrahi J, Ring H, Susak Z, Hakim N. Standing sway and weight-bearing distribution in people with bellow-knee amputations. Arch Phys Med Rehabil, 1992; 73:174-8.

Jekel JF, Elmore JG, Katz DL. Epidemiologia, bioestatística e medicina preventiva. Porto Alegre, RS: Artmed Editora SA; 2002.

Jorge Filho Donaldo. Próteses ortopédicas de baixo custo: estudo crítico do pé de Jaipur nos amputados transtibiais [dissertação] . São Paulo: Escola Paulista de Medicina, Universidade Federal de São Paulo; 1996.

Jorge Filho D, Lourenço C, Battistella LR. Hemartroses recidivantes do tornozelo em hemofilia - diagnóstico funcional pela podobarometria dinâmica computadorizada e uso profilático de órteses para os pés: relato de um caso. Acta Fisiatr, 2001; 8(1): 34-44.

Katoh Y, Chao EYS, Laughman RPT, Schneider E, Morrey BF. Biomechanical analysis of foot function during gait and clinical applications. Clin Orthop, 1983; 177:23-33.

Kreuz W, Escuriola-Ettingshausen C, Funk M, Schmidt H, Kornhuber B. When should prophylactic treatment in patients with haemophilia $A$ and $B$ start? - The German experience. Haemophilia, 1998; 4(4): 413-7.

Li C, laishi K, Shiba N, Tagawa Y, Maeda T, Matsuo S, Goto T, lamanaka K. Biomechanical Evaluation of Foot Pressure and Loading Force during Gait in Rheumatoid Arthritic Patients with and without Foot Orthosis. Kurume Med J, 2000; 47: 211-7. 
Liesner RJ, Khair K, Hann IM. The impact of prophylactic treatment on children with severe haemophilia. Br J Haematol, 1996; 92: 973-8.

Ljung RCR. Prophylactic treatment in Sweden: overtreatment or optimal model? Haemophilia, 1998; 4: 409-2.

Lord M, Smith DM. Foot loading in amputee stance. Prosthet Orthot Int, $1984 ; 8: 159-164$

Marsh JS, Daigneault JP. Ankle injuries in the pediatric population. Curr Opin Pediatr. 2000; 12 (1): 52-60.

Matsusaka N, Yokoyama S, Tsurusaki T, Inokuchi S, Okita M. Effect of ankle disk training combined with tactile stimulation to the leg and foot on functional instability of the ankle. Am J Sports Med. 2001; 29(1):25-30.

Mattacola CG, Dwyer MK. Rehabilitation of the ankle after acute sprain or chronic instability. J Athl Train, 2002; 37(4): 413-29.

Molho P, Rolland N, Lebrun T, Dirat G, Courpied P, Croughs T, et al. Epidemiological survey of the orthopaedic status of severe haemophilia $A$ and B patients in France. Haemophilia, 2000; 6: 23-32.

Mueller MJ, Strube MJ. Generalizability of in-shoe peak pressure measures using the F-scan system. Clin Biomech, 1996; 3:159-64.

Mueller MJ, Sinacore DR, Hoogstrate S, Daly L. Hip and ankle walking strategies: effect on peak plantar pressures and implications for neuropatic ulceration. Arch Phys Med Rehabil, 1994; 75:1196-200.

Nishikawa T, Kurosaka M, Mizuno K, Grabiner M. Protection and performance effects of ankle bracing. Int Orthop. 2000; 24:285-8. 
Orlin MN, McPoil TG. Plantar Pressure Assessment. Phys Ther, 2000; 80(4): 399-409.

Querol-Fuentes F, Lopez-Cabarcos C, Aznar-Lucea JA. Gait corrective devices IN: Rodrigues-Merchán EC, Goddard NJ, Lee CA. Musculoskeletal Aspects of Haemophilia. Oxford Blackwell Science; 2000. p.197-211.

Querol-Fuentes F, Aznar-Lucea JA, Haya S, Cid A. Orthoses in Haemophilia. Haemophilia, 2002; 8: 407-12.

Ribbans WJ, Phillips MA. Hemophilic ankle arthropathy. Clin Orthop Rel Res. 1996; (328): 39-45.

Ribbans WJ, Giangrande P, Beeton K. Conservative treatment of hemarthrosis for prevention of hemophilic synovitis. Clin Orthop Rel Res 1997; (343): 12-8.

Rodriguez-Merchán EC. Effects of hemophilia on articulations of children and adults. Clin Orthop Rel Res, 1996; (328):7-13.

Rodriguez-Merchán EC. Pathogenesis, early diagnosis and prophylaxis for chronic hemophilic synovitis. Clin Orthop Rel Res, 1997; (343):6-11.

Roosendaal G, Van Den Berg HM, Lafeber FPJG, Bijlsma JWJ. Bloodinduced joint damage: an overview of musculoskeletal research in haemophilia. In: Rodriguez-Merchan EC, Goddard NJ, Lee CA. Musculoskeletal aspects of haemophilia. Oxford Blackwell Science, 2000. p.18-26.

Rose NE, Feiwell LA, Cracchiolo A. A method for measuring foot pressures using a high resolution, computerized insole sensor: The effect of heel wedges on plantar pressure distribution and center of force. Foot Ankle, 1992; 13(5): 263-70. 
Safran MR, Benedetti RS, Bartolozzi AR, Mandelbaum BR. Lateral ankle sprains: a comprehensive review Part 1: etiology, pathoanatomy, histopathogenesis, and diagnosis. Med Sci Sports Exerc, 1999; 31(7): 429-37.

Scherer PR, Sobiesk GA. The center of pressure index in the evaluation of foot orthoses in shoes. Clin Podiatr Med Surg, 1994; 11(2): 355-63.

Schramm W, Berger K. Linking medicine and economics: health economics and quality of life in haemophilia care. Haemophilia, 2002; 8: 217-20.

Srivastava A, Chuansumrit A, Chandy M, Duraiswamy G, Karagus C. Management of haemophilia in the developing world. Haemophilia, 1998; 4(4): 474-80.

Steven MM, Yogorajah S, Madhok R, Forbes CD, Sturrock RD. Haemophilic Arthritis. Q J Med. 1986; 226:181-97.

Stover CN. Air stirrup management of ankle injuries in the athlete. Am J Sports Med. 1980: 8 (5): 360-5.

Summers GD, Morrison JD, Cochrane GM. Foot loading characteristics of amputees and normal subjects. Prosthet Orthot Int, 1987; 11: 33-9.

Szucs TD et al. Resource utilization in haemophiliacs treated in Europe: results from the European Study on Socioeconomic Aspects of Haemophilia Care. Haemophilia, 1998; 4: 498-501.

Vaes PH, Duquet W, Casteleyn PP, Handelberg F, Opdecam P. Static and dynamic roentgenographic analysis of ankle stability in braced and nonbraced stable and functionally unstable ankles. Am J Sports Med. 1998; 26(5):692-702. 
Vittas D, Larsen TK, Jansen EC. Body sway in bellow-knee amputees. Prosthet Orthot Int, 1986; 10:139-41. 